\title{
CSU-CHILL Polarimetric Radar Measurements from a Severe Hail Storm in Eastern Colorado
}

\author{
J. Hubbert, V. N. Bringi, And L. D. CAREY \\ Colorado State University, Fort Collins, Colorado \\ S. BOLEN \\ Rome Laboratory, U.S. Air Force, Rome, New York
}

(Manuscript received 4 November 1996, in final form 20 November 1997)

\section{ABSTRACT}

\begin{abstract}
Polarimetric radar measurements made by the recently upgraded CSU-CHILL radar system in a severe hailstorm are analyzed permitting for the first time the combined use of $Z_{h}, Z_{\mathrm{DR}}$, linear depolarization ratio (LDR), $K_{\mathrm{DP}}$, and $\rho_{h v}$ to infer hydrometeor types. A chase van equipped for manual collection of hail, and instrumented with a rain gauge, intercepted the storm core for $50 \mathrm{~min}$. The period of golfball-sized hail is easily distinguished by high LDR (greater than or equal to $-18 \mathrm{~dB}$ ), negative $Z_{\mathrm{DR}}$ (less than or equal to $-0.5 \mathrm{~dB}$ ), and low $\rho_{h v}$ (less than or equal to 0.93) values near the surface. Rainfall accumulation over the entire event (about $40 \mathrm{~mm}$ ) estimated using $K_{\mathrm{DP}}$ is in excellent agreement with the rain gauge measurement. Limited dual-Doppler synthesis using the CSU-CHILL and Denver WSR-88D radars permit estimates of the horizontal convergence at altitudes less than $3 \mathrm{~km}$ above ground level (AGL) at 1747 and 1812 mountain daylight time (MDT). Locations of peak horizontal convergence at these times are centered on well-defined positive $Z_{\mathrm{DR}}$ columns. Vertical sections of multiparameter radar data at 1812 MDT are interpreted in terms of hydrometeor type. In particular, an enhanced LDR "cap" area on top of the the positive $Z_{\mathrm{DR}}$ column is interpreted as a region of mixed phase with large drops mixed with partially frozen and frozen hydrometeors. A positive $K_{\mathrm{DP}}$ column on the the western fringe of the main updraft is inferred to be the result of drops $(1-2 \mathrm{~mm})$ shed by wet hailstones. Swaths of large hail at the surface (inferred from LDR signatures) and positive $Z_{\mathrm{DR}}$ at $3.5 \mathrm{~km}$ AGL suggest that potential frozen drop embryos are favorably located for growth into large hailstones. Thin section analysis of a sample of the large hailstones shows that $30 \%-40 \%$ have frozen drop embryos.
\end{abstract}

\section{Introduction}

The CSU-CHILL radar was recently modified to a two transmitter/two receiver configuration permitting the measurement of the polarimetric covariance matrix in the horizontal/vertical polarization basis. A new dualpolarized antenna with excellent main lobe matching, superior sidelobe levels (worst case of $-27 \mathrm{~dB}$ in any $\phi$ plane), and excellent cross-polar characteristics (linear depolarization ratio system limit of approximately $-34 \mathrm{~dB}$ ) permits accurate measurement of polarimetric variables such as differential reflectivity $\left(Z_{\mathrm{DR}}\right)$, linear depolarization ratio (LDR), differential phase $\left(\Phi_{\mathrm{DP}}\right)$, and copolar correlation coefficient $\left(\rho_{h v}\right)$ [see Doviak and Zrnić (1993) for a discussion of these polarimetric variables]. For the past two summers the radar has been used to obtain high-resolution measurements of hydro-

Corresponding author address: Dr. John Hubbert, Department of Electrical Engineering, Colorado State University, Fort Collins, CO 80523-1373.

E-mail: hubbert@engr.colostate.edu meteors within convective precipitation shafts in conjunction with instrumented chase vans. On 7 June 1995, a severe hailstorm at close range (less than $35 \mathrm{~km}$ ) exhibiting supercell characteristics was scanned by the radar with volume scans available every $4-5 \mathrm{~min}$ and was intercepted by a chase van with a roof-mounted hail collection net and a rain gauge. Total rainfall accumulation, visual observation of hydrometeor type/size, and time-resolved hailstone size distribution over a 5-min period just prior to the intense hailfall were available for analysis. Limited dual-Doppler synthesis of horizontal winds was possible with the Denver WSR-88D radar. Our goals in this paper are 1) to correlate polarimetric measurements near the chase van location with in situ observations of hail and rain, 2) to infer particle type and storm structure from the polarimetric signatures, and 3) to identify the sources of raindrop embryos via the polarimetric signatures. In particular, a positive $Z_{\mathrm{DR}}$ is discussed, and a positive $K_{\mathrm{DP}}$ column signature is shown that we believe results from raindrops shed from wet hail.

The supercell storm reported here is typical of severe storms in a postfrontal upslope flow found in the eastern 
plains of Colorado and, in particular, is similar to the supercell studied by Conway and Zrnić (1993). They used dual-Doppler analysis and particle trajectory calculations to infer the origin of the positive $Z_{\mathrm{DR}}$ column and its importance to embryo and hail production. Höller et al. (1994) also examined the positive $Z_{\mathrm{DR}}$ column of a hybrid-type storm in southern Germany using a Cband dual-polarized radar. They found that the main source of drops within the positive $Z_{\mathrm{DR}}$ column originated with melted graupel formed in the new growing cells that fell below the melting level and then were recirculated in regions of higher updraft speeds. Brandes et al. (1995) analyzed T-28 aircraft penetration through a positive $Z_{\mathrm{DR}}$ column (in a multicellular storm in Colorado) and found that it was coincident with the updraft and that it contained mixed-phase precipitation with a low concentration of very large raindrops. Their trajectory analysis revealed that the drops originated with partially or totally melted particles from a feeder band located within the storm inflow region. Bringi et al. (1996) also analyzed one later T-28 penetration through another positive $Z_{\mathrm{DR}}$ column within the same storm complex (on the inflow side) that was centered on the updraft region with predominantly liquid drops (up to 7-mm diameter). Brandes et al. (1995) concluded that the $Z_{\mathrm{DR}}$ column in their study did not play a role in hail production since updraft speeds were not sufficient to loft large drops. However, they also noted that in other regions of the storm where $Z_{\mathrm{DR}}$ columns were more closely tied to updraft centers, the frozen drop embryos originating in the column may be relevant to hail growth [e.g., the later T-28 penetration analyzed in Bringi et al. (1996)].

Miller et al. $(1988,1990)$ analyzed hail growth in two supercell storms in Montana using multiple-Doppler synthesis and particle growth trajectory calculations. Miller et al. (1990) also showed the importance of a low-level curtain of drizzle across the inflow region with some of the drops entering the main updraft area in straight-line patterns that had the potential to grow into very large hail. They point to the importance of embryo transport across the low-level inflow to the production of large hail in their case study. The possible role of the positive $Z_{\mathrm{DR}}$ column in providing these embryos is further documented in this paper. Another important source of embryos is via shedding of millimeter-sized drops from wet hailstones (Lesins et al. 1980; Joe and List 1984; Rasmussen and Heymsfield 1987a,b; Miller et al. 1990). A positive $K_{\mathrm{DP}}$ column is identified in this paper, which likely results from water drops shed from wet hail.

Previous multiparameter radar analyses have combined some polarimetric and/or dual-wavelength-based measurements to infer hydrometeor types/amounts (see, e.g., Torlaschi et al. 1984; Tuttle et al. 1989; Herzegh and Jameson 1992). Höller et al. (1994) used a combination of $Z_{\mathrm{DR}}$ and LDR measurements, while Zrnić et al. (1993) used $Z_{\mathrm{DR}}, K_{\mathrm{DP}}$, and $\rho_{h v}$ in an empirical scheme of hydrometeor classification in hailstorms. Carey and Rutledge (1998) use five polarimetric variables, $Z_{h}, Z_{\mathrm{DR}}$, LDR, $K_{\mathrm{DP}}$, and $\rho_{h v}$, to analyze the supercell case described in this paper with an emphasis on electrification, and they provide a version of bulk hydrometeor classification in tabular form. In this paper, this set of polarimetric measurements is used together with a synthesis of past observations, scattering models' results (e.g., Aydin and Zhao 1990), and in situ measurements to interpret the radar signatures. A discussion of these variables is given in appendix B; further discussion can be found in Doviak and Zrnić (1993), who give a table of classification based on a complete polarimetric dataset.

This paper is organized as follows. Following an overview of the synoptic-scale environment in section 2 , we study storm structure in section 3 via constant altitude plan position indicator (PPI) cross sections and selected vertical sections. Surface radar measurements over the chase van location are compared with in situ observations in section 4. A summary is given in section 5. Five appendices are included that describe the CSUCHILL radar, data processing methods, and data quality issues.

\section{Synoptic-scale environment}

The meteorological conditions of 7 June 1995 along the Front Range of northeastern Colorado closely resembled those described by Doswell (1980) for High Plains severe thunderstorms. The key ingredients were 1) a quasi-stationary front south of the area through the Oklahoma-Texas panhandle; 2$)$ steadily increasing surface dewpoints during the day in excess of $45^{\circ} \mathrm{F}\left(7.2^{\circ} \mathrm{C}\right)$ with maximum values reaching $53^{\circ} \mathrm{F}\left(11.7^{\circ} \mathrm{C}\right)$ associated with upslope flow, which veered from northeasterly to southeasterly during the day at $2-5 \mathrm{~m} \mathrm{~s}^{-1}$; and 3) strong southwesterly flow at $500 \mathrm{mb}$ in excess of $20 \mathrm{~m}$ $\mathrm{s}^{-1}$ associated with a closed low in the Great Basin. At $300 \mathrm{mb}$ a jet streak rotated through central Colorado, placing the area of interest in the right exit region, which is often a synoptically unfavorable location (i.e., subsidence). However, diffluent flow was present at this level, which is dynamically favorable for thunderstorm development. Note that severe thunderstorms had occurred on the previous day (6 June 1995) and were, therefore, expected on this day since meteorological conditions for severe storms typically persist for several days (Doswell 1980).

Severe thunderstorms often take the form of supercells (Browning 1964) on the High Plains during late spring. These storms are usually characterized by a quasi-steady-state updraft-downdraft pair, deviate movement to the right of the mean winds (the so-called rightmover), the presence of a Bounded Weak Echo Region (BWER), and deep mesocyclonic flow (Moller et al. 1994). The severe thunderstorm studied in this paper possessed all of these typical supercell characteristics. 


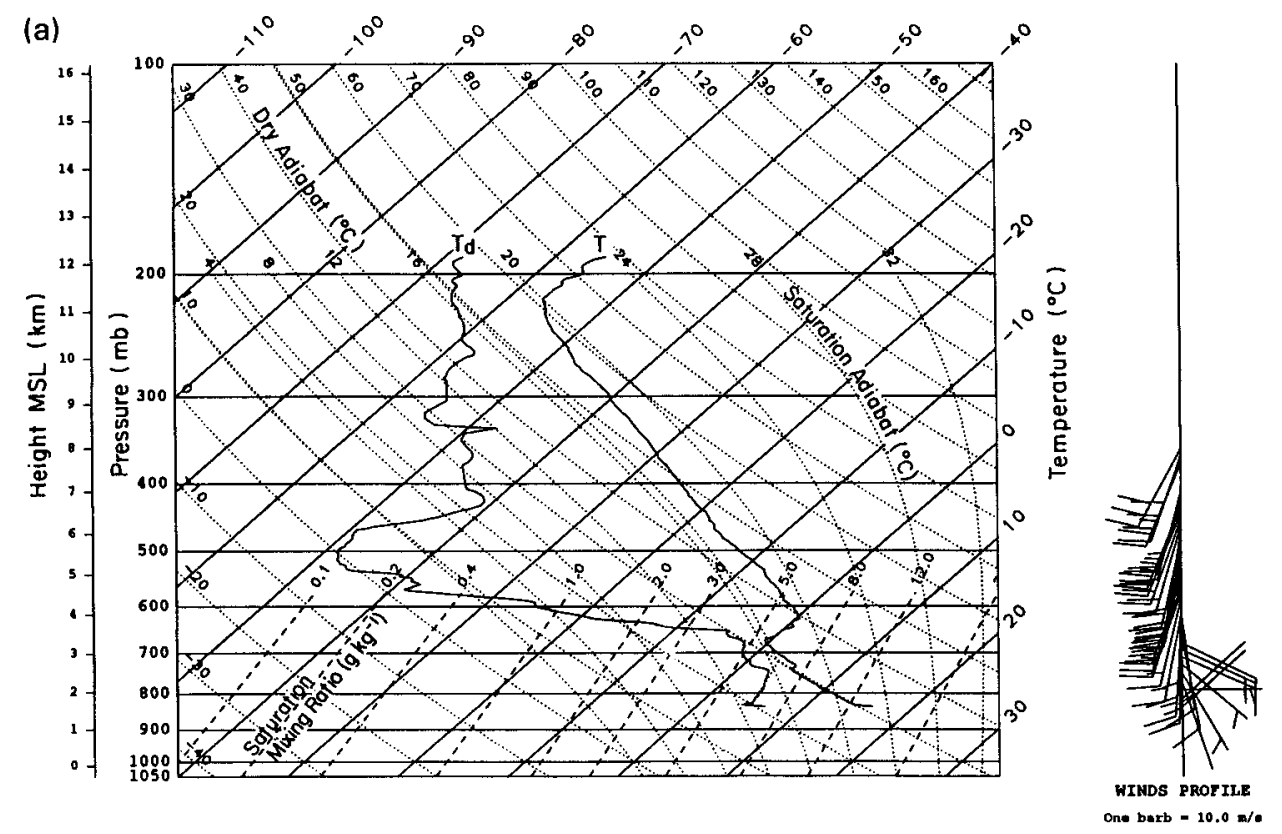

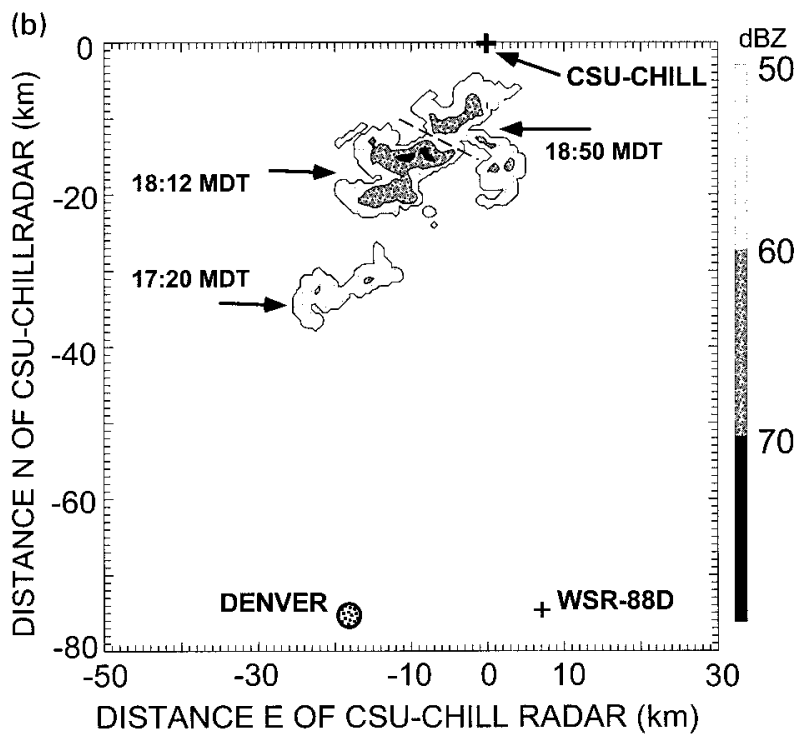

The late morning sounding shown in Fig. 1a was taken near Denver, Colorado, at 1114 mountain daylight time (MDT) (or 1714 UTC) and is characterized by an adiabatic environment from the surface to a capping frontal inversion at $680 \mathrm{mb}$ with a relatively dry layer at the surface and a relatively moist layer from about $750 \mathrm{mb}$ to the bottom of the inversion. The $0^{\circ} \mathrm{C}$ isotherm is located at $4.0 \mathrm{~km}$ above mean sea level. Above the inversion, the environment was conditionally stable up to $400 \mathrm{mb}$ with the tropopause located at $210 \mathrm{mb}$ and was characterized by a deep, midlevel dry layer centered on $500 \mathrm{mb}$. Due to the presence of this inversion, there was substantial convective inhibition (Bluestein 1993) of $-725 \mathrm{~J} \mathrm{~kg}^{-1}$, which was evident by the fact that
FIG. 1. (a) Skew $T-\log p$ plot of Denver, CO, radiosonde data from 1114 MDT (1714 UTC) on 7 June 1995. Temperature and dewpoint temperature are in degrees Celsius. Wind data, which terminated at $360 \mathrm{mb}$, is in meters per second. (b) CAPPI of reflectivity $\left(Z_{h}\right)$ at 0.5 $\mathrm{km}$ at 1720, 1812, and 1850 MDT. Locations of CSU-CHILL and Denver WSR-88D radars are marked. convection was essentially capped until about 2200 UTC. During the day there was significant moistening in the boundary layer due to the upslope flow. To more accurately represent the preconvective environment, which was about $5 \mathrm{~h}$ following the actual rawinsonde release, the sounding was modified to account for 1) moistening of the surface dewpoint to a maximum of $\left.11.7^{\circ} \mathrm{C}, 2\right)$ warming of the surface to a maximum of $22^{\circ} \mathrm{C}, 3$ ) assuming a deep mixed layer up to the convective condensation level at about $715 \mathrm{mb}$, and 4) eliminating the frontal inversion to allow the available convective energy to be explosively released. These assumptions merely allow an estimate of the maximum potential energy in the atmosphere, that is, convective 

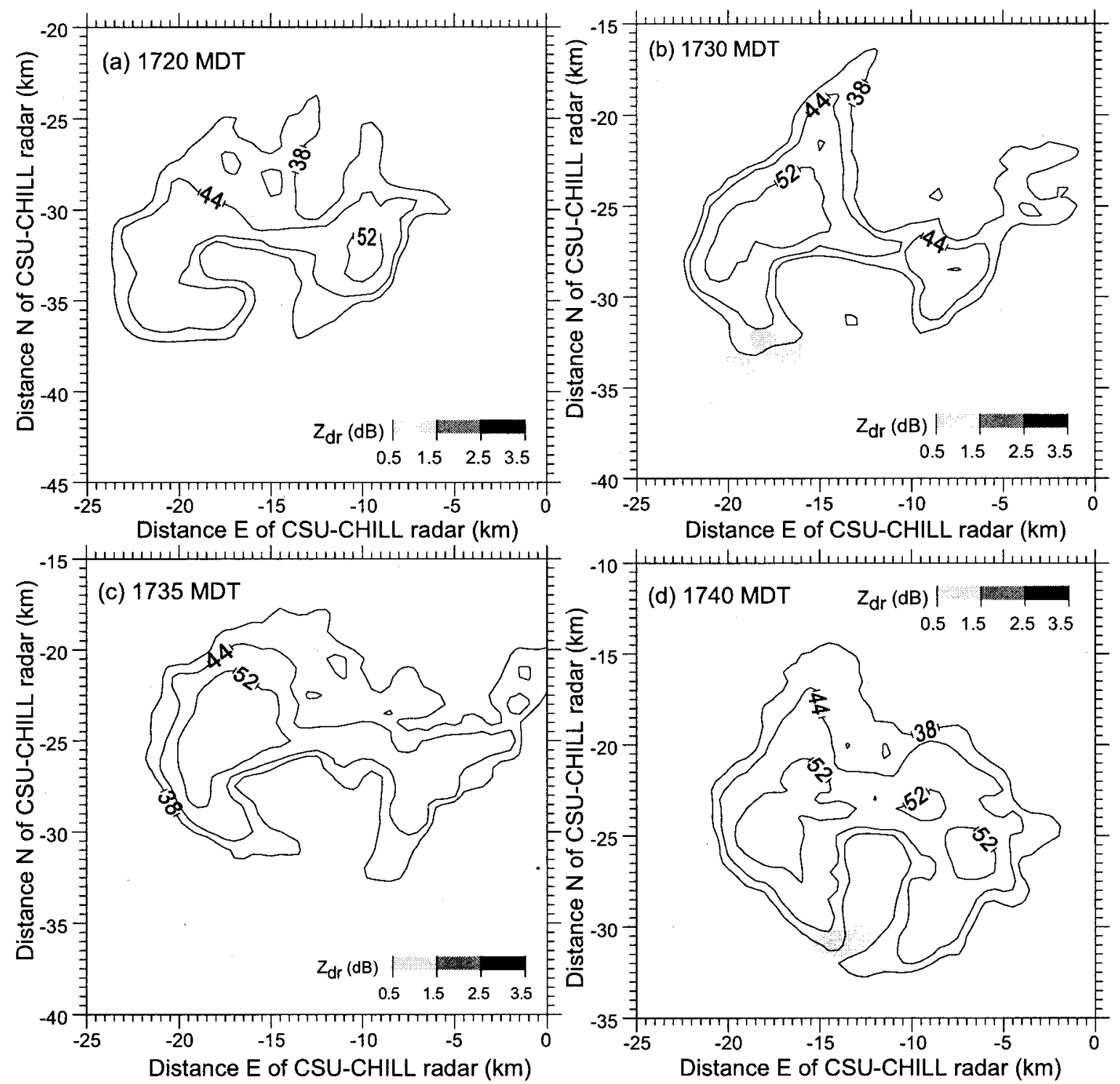

FIG. 2. CAPPI sections of reflectivity $\left(Z_{h}\right)$ from CSU-CHILL at 5-km altitude (AGL). Grayscale filled contours of $Z_{\mathrm{DR}}$ from 3-km AGL are shown as an overlay. (a)-(j) Times from 1720 to 1825 MDT. The $Z_{h}$ contours are at 38, 44, 52, and $60 \mathrm{dBZ}$.

available potential energy (CAPE) of $2268 \mathrm{~J} \mathrm{~kg}^{-1}$, which is conducive to the formation of severe thunderstorms.

The potential for supercell thunderstorms can be represented by the bulk Richardson number $[\mathrm{Ri}=\mathrm{CAPE} /$ $\left.\left(U^{2} / 2\right)\right]$, where $U$ is a measure of the pressure weighted vertical wind shear in the lowest $6 \mathrm{~km}$ (Weisman and Klemp 1982, 1984). For the present case, the winds veered with height from southeasterly to southwesterly and were characterized by moderate shear $\left(20 \mathrm{~m} \mathrm{~s}^{-1}\right)$ in the lowest $6 \mathrm{~km}$ of the troposphere. From the 1714 UTC modified sounding, $\mathrm{Ri}$ is estimated to be about 11.3, and, according to Weisman and Klemp (1982, 1984), magnitudes of Ri between 10 and 40 are highly suggestive of supercellular growth.

\section{Storm structure and evolution}

\section{a. Constant altitude PPI sections}

Figure $1 \mathrm{~b}$ shows the analysis region and the locations of the CSU-CHILL radar (grid origin) and the Denver WSR-88D. The storm cell of interest (there were two supercells) is shown via $Z_{h}$ contours at 0.5 -km constantaltitude plan position indicator (CAPPI) at 1720, 1812, and 1850 MDT. The hail, wind, and heavy rain caused over \$28 million dollars damage in Weld County, and there was a tornado report between 1812 and 1847 MDT. The maximum mass hail flux from the supercell analyzed herein was between 1745 and 1830 MDT (Carey and Rutledge 1998). Limited dual-Doppler synthesis was possible at 1747 and 1812 MDT. 

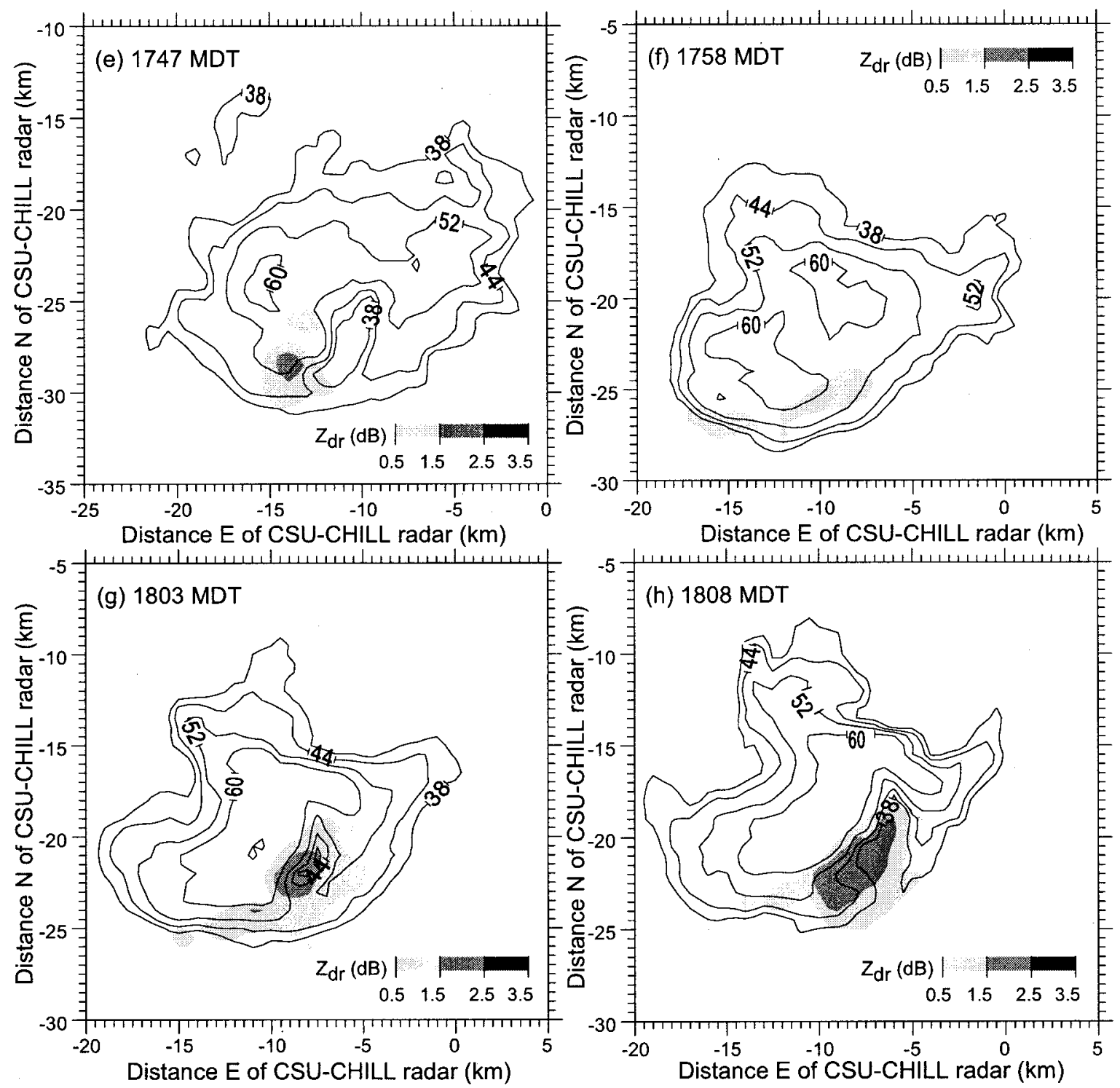

FIG. 2. (Continued)

Figures $2 \mathrm{a}-\mathrm{j}$ show the general evolution of the storm and the positive $Z_{\mathrm{DR}}$ column from 1720 to 1825 MDT via CAPPIs of reflectivity $\left(Z_{h}\right)$ with differential reflectivity $\left(Z_{\mathrm{DR}}\right)$ overlaid in grayscale (note that the CAPPI time spacings are not regular). Henceforth, all times will be MDT, and all altitudes will be above ground level (AGL), unless otherwise indicated. Data processing methods are described in appendix A. The $Z_{h}$ is from $5-\mathrm{km}$ altitude, while the $Z_{\mathrm{DR}}$ is from $3-\mathrm{km}$ altitude. This is done to more clearly illustrate the relationship between the location of the $Z_{\mathrm{DR}}$ column and the updraft core assumed here to be marked by the weak echo region (WER) on the southeast side of the cell, which is typically bounded during this time period. In general, the storm intensity and the size of the $Z_{\mathrm{DR}}$ column increase with time. Closer inspection of the $Z_{\mathrm{DR}}$ column reveals that it actually fluctuated in volume and magnitude during 1720-1803 (i.e., it grew in three successive "pulses" subsiding after the first two) after which it remained large and widespread through 1825 . The first significant volume of $Z_{\mathrm{DR}}$ column was observed at 1730 and a second pulse was observed at 1747. At 1730 the top of the positive $Z_{\mathrm{DR}}$ column exceeded $3.5 \mathrm{~km}$ AGL and was located in the the reflectivity notch and BWER of the supercell where updrafts are likely to be strong. Therefore, we believe that drop embryos were being advected into the storm complex at least by 1730 . In general, before 1803 the center $Z_{\mathrm{DR}}$ column is located a few kilometers to the south-southwest of the center reflectivity vault region, which, it is believed, is void of significant precipitation because of the strong updraft found there (Browning 1977). It is consistent then that 

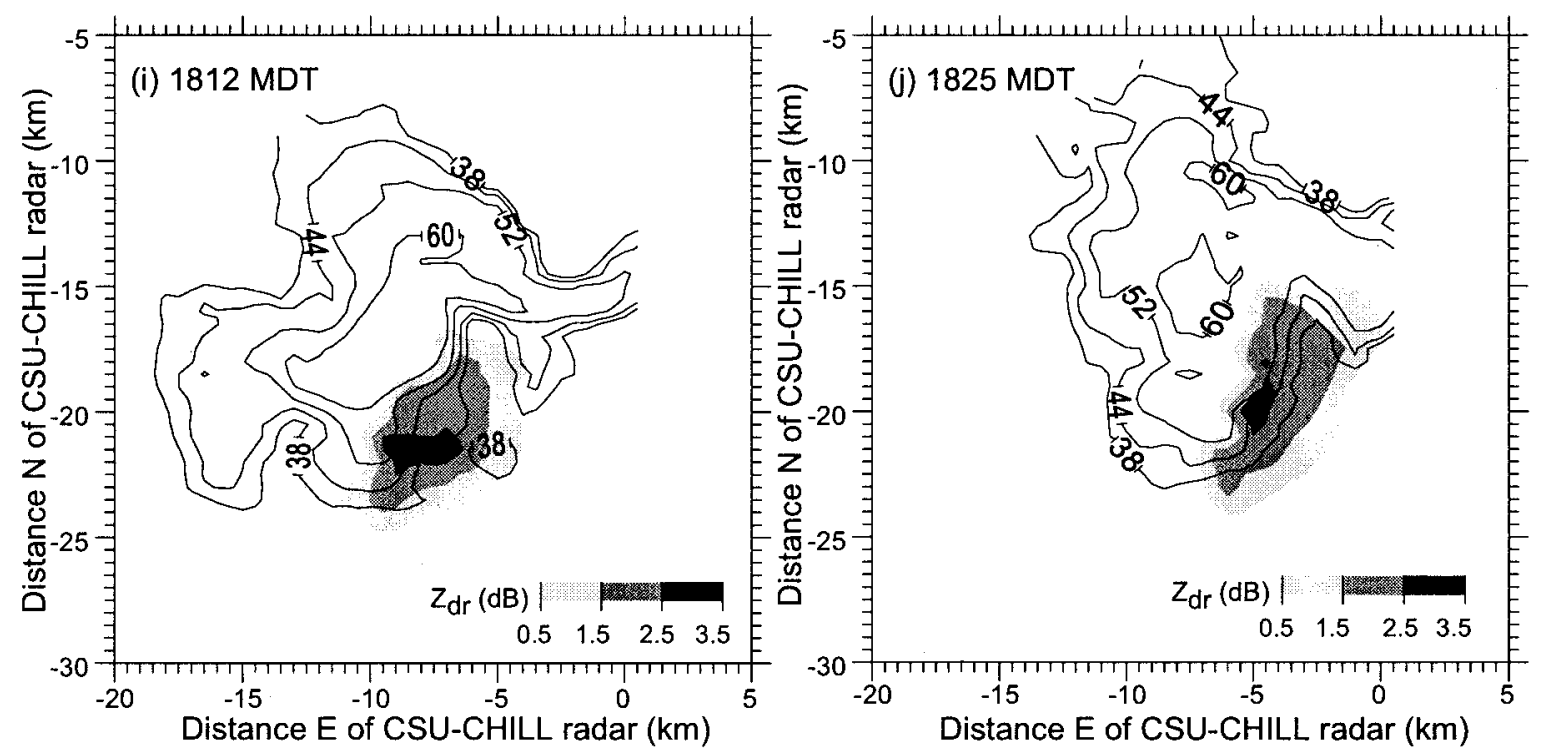

FIG. 2. (Continued)

the $Z_{\mathrm{DR}}$ column first appears in an area of weaker updraft southwest of the center of the reflectivity vault. After 1803 , the $Z_{\mathrm{DR}}$ column occupies nearly the entire WER/ vault region, but with the largest portion of the $Z_{\mathrm{DR}}$ column still located south-southwest of the vault, indicating a very wide region of updraft at these times. Other important features of the positive $Z_{\mathrm{DR}}$ column are that it originates in conjunction with the reflectivity "hook," which is another characteristic of supercells that is caused by the cyclonic rotation of the storm (Browning 1977) (seen in lower-level $Z_{h}$ CAPPIs, e.g., Fig. 3a) and that it first appears underneath the upwind reflectivity overhang. This is further clarified with limited (low level) wind vector analysis and high-resolution range-height indicator (RHI) scans discussed next.

Limited dual-Doppler analysis was possible at 1747 and 1812 MDT using the CSU-CHILL and Denver WSR-88D radars with baseline of $75 \mathrm{~km}$ (see appendix $\mathrm{D}$ for details). The horizontal velocity vector at low altitudes $(0.5-3 \mathrm{~km})$ was synthesized using low elevation angle PPI data from the two radars. Analyses at other times were not possible either because the radar scans were not synchronized or because the storm moved through the baseline. Low-level horizontal convergence was calculated as a proxy for updraft location and relative strength. Figure $3 \mathrm{a}$ shows earth-relative wind vectors at 1748 together with grayscale-filled $Z_{h}$ contours from $3 \mathrm{~km}$. At this time, the storm was nearly stationary having slowed down and was moving only about 2-4 $\mathrm{m} \mathrm{s}^{-1}$ (very difficult to estimate); therefore, only the earth-relative velocity is given in Figs. 3 and 4. The reflectivity notch [near $(-12,-26 \mathrm{~km})]$ coincides with the main inflow into the storm, which has a cyclonic curvature. Figure $3 \mathrm{~b}$ shows contours of horizontal convergence at $2.5 \mathrm{~km}$ together with contours of reflectivity. The area of horizontal convergence $(>3.5$ $\times 10^{-3} \mathrm{~s}^{-1}$ ) is oriented along a northeast-southwest line across the reflectivity notch with positive $Z_{\mathrm{DR}}$ slightly displaced to the southwest of the peak convergence area. The center of the BWER is at $(-11,-27 \mathrm{~km})$, marked in Fig. 3b with a "+," and it lies within the area of horizontal convergence. Thus, all three updraft indicators, BWER, wind convergence, and $Z_{\mathrm{DR}}$ column, place the updraft in the same general area, and thus we infer that the main updraft is in this region.

Figure 4 shows similar results at 1812 MDT. Inflow along the southeast side with cyclonic curvature around the areas of $Z_{h}>60 \mathrm{dBZ}$ can be noted. The area of horizontal convergence in Fig. $4 \mathrm{~b}$ is now oriented along a more north-south axis across the main inflow with the convergence maxima coinciding with the positive $Z_{\mathrm{DR}}$ area. Note the larger $Z_{\mathrm{DR}}$ magnitudes $(>2.5 \mathrm{~dB})$ at 1812 compared to 1747 MDT (Fig. 3b). The center of the reflectivity notch in Figs. $4 \mathrm{a}, \mathrm{b}$ [near $-7,-17 \mathrm{~km}$ ] is to

FIG. 3. (a) Dual-Doppler synthesized horizontal winds at 1748 MDT from Denver WSR-88D and CSU-CHILL radars at 3-km altitude (AGL). Grayscale filled contours of $Z_{h}$ from CSU-CHILL start at $20 \mathrm{dBZ}$ and increment by $10 \mathrm{~dB}$. The dark, solid line shows the $204^{\circ}$ azimuth direction along which the RHI scan data is shown in Fig. 5. The circle marks a range of $30 \mathrm{~km}$, while the slant bars mark the ranges of 18 and $38 \mathrm{~km}$. Grid origin is at the CSU-CHILL location. Wind vectors are earth relative. (b) Solid contours represent $Z_{h}$. Dashed contours show selected values of the horizontal convergence field. Grayscale filled contours of $Z_{\mathrm{DR}}$ start at $0.5 \mathrm{~dB}$ with step $=0.5 \mathrm{~dB}$. The " $\times$ " marks the chase van location. The "+" marks the approximate center of the bounded weak echo region at $4.5 \mathrm{~km}$ AGL. 

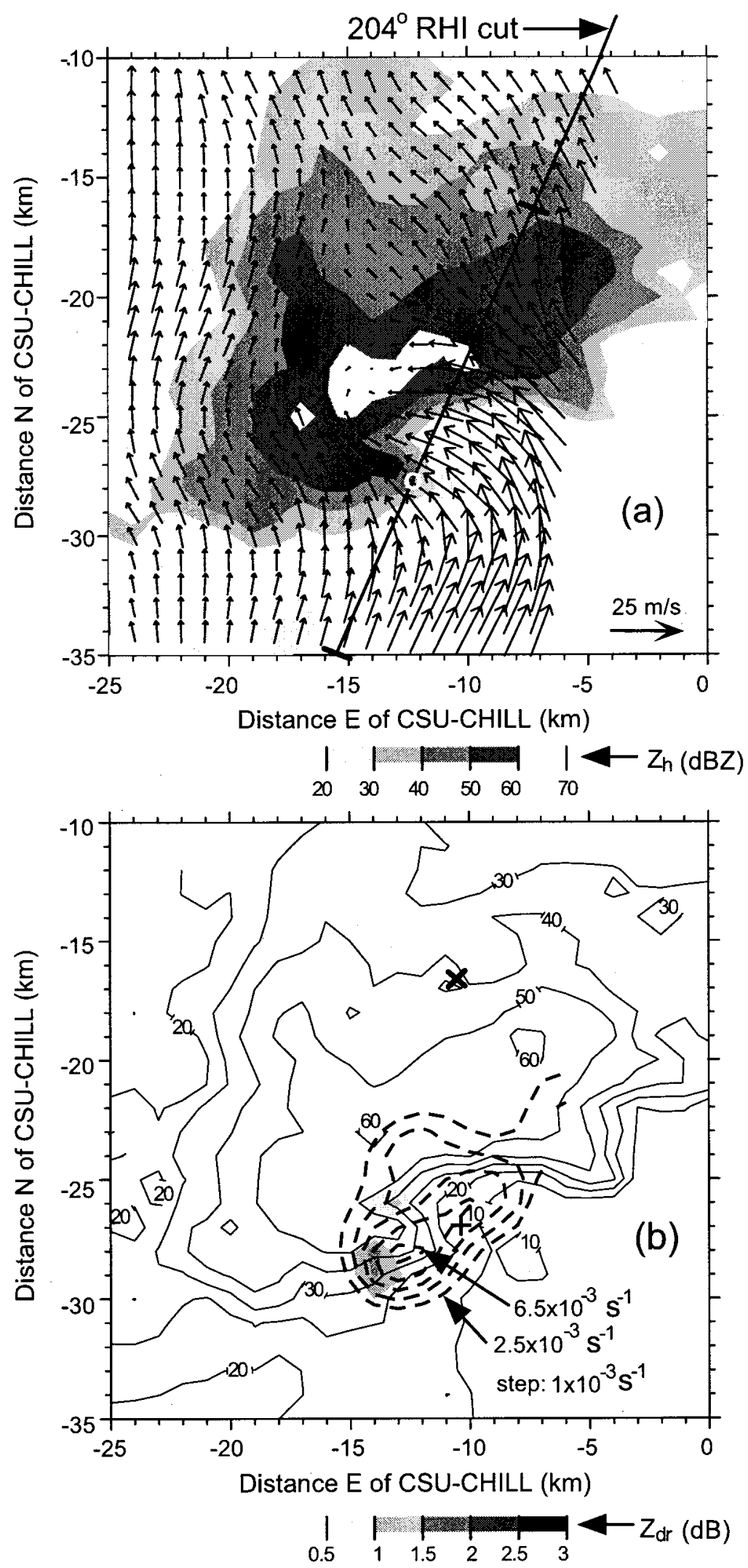

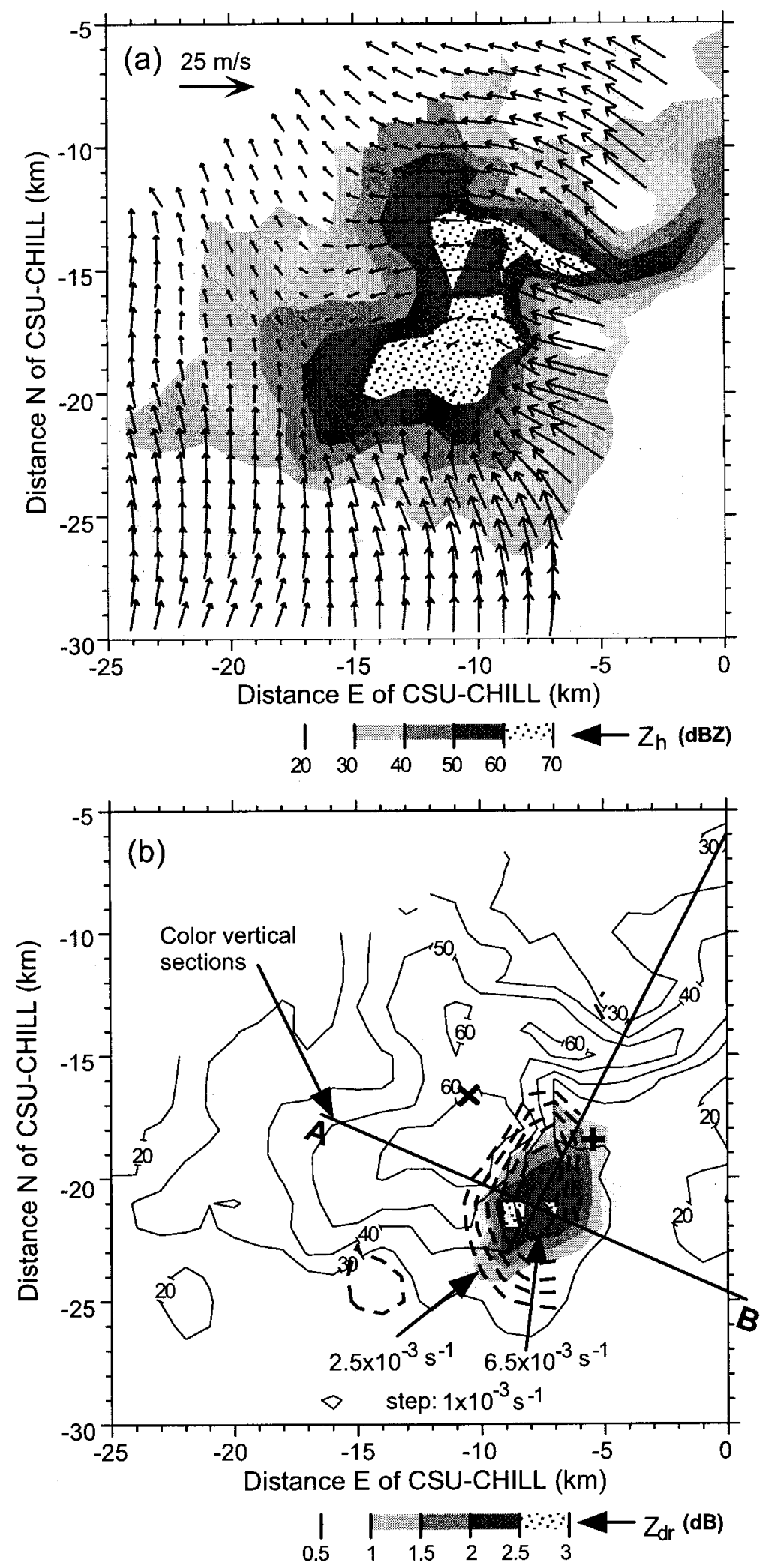

FIG. 4. (a) As in Fig. 3a except at 1812 MDT. (b) As in Fig. 3b except at 1812 MDT. The orthogonal pair of solid lines shows rotated Cartesian axes along which vertical sections are shown in Fig. 6. The "+" marks the approximate center of the bounded weak echo region at $5.5 \mathrm{~km}$ AGL. (c) As in (b) except grayscale filled contours of $K_{\mathrm{DP}}$ starting at $0.25^{\circ} \mathrm{km}^{-1}$ with step $=0.25^{\circ} \mathrm{km}^{-1}$. 


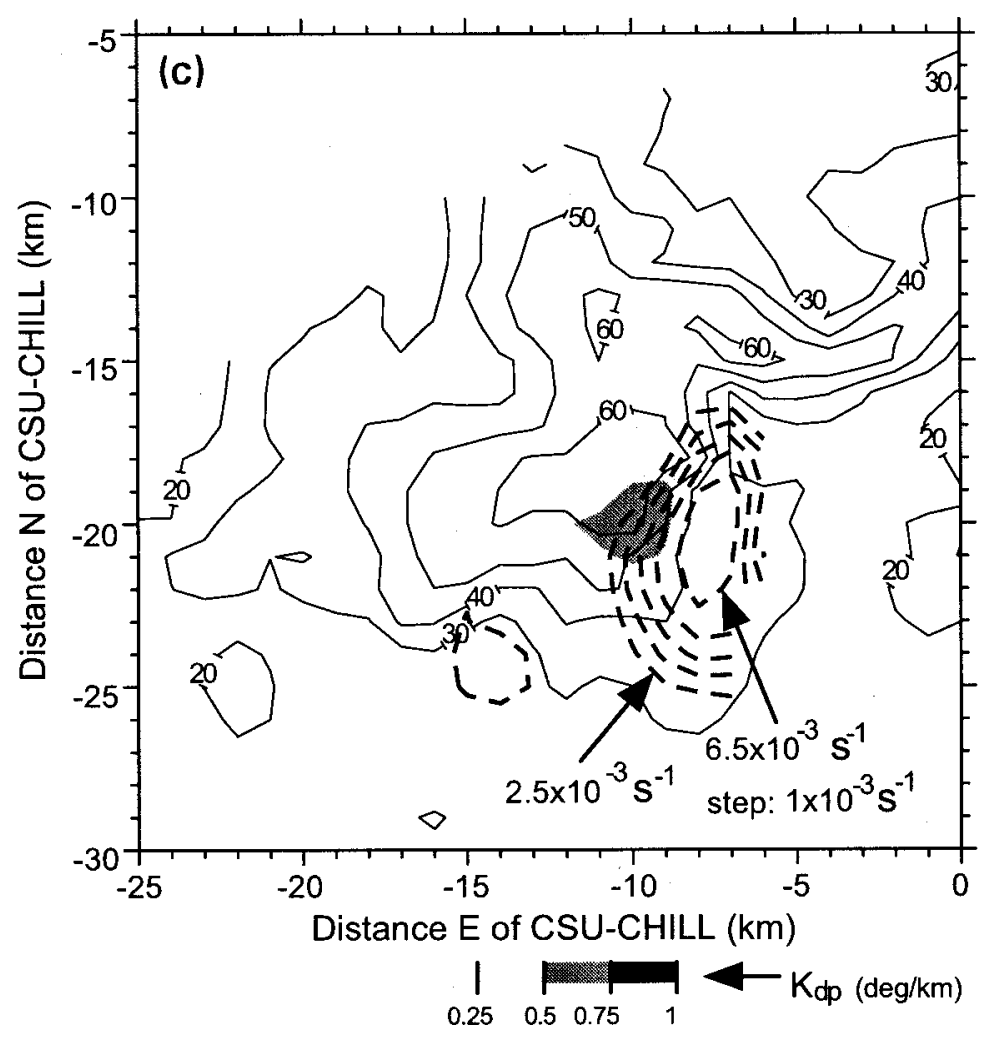

FIG. 4. (Continued)

the north of the peak convergence $/ Z_{\mathrm{DR}}$ areas at this level. Thus, we infer a broad region of updraft along a northsouth axis across the main inflow. Examination of the 5.5-km CAPPI of reflectivity (not shown here) reveals that the BWER is quite broad (elongated along and over the $Z_{\mathrm{DR}}$ column) and centered at about $(-5.5,-18.5$ km) (marked by a " +" in Fig. 4b); however, the BWER is not as well defined at this time and is characterized by $30<Z_{h}<40 \mathrm{dBZ}$. The core of the $Z_{\mathrm{DR}}$ column is about $3.5 \mathrm{~km}$ to the southwest of the center of the BWER. Figure 4c (to be discussed later) shows areas of positive $K_{\mathrm{DP}}$ (shaded) on the west fringe of the convergence area.

Conway and Zrnic (1993) were the first to study the origin of a positive $Z_{\mathrm{DR}}$ column in a supercell hailstorm in Colorado using dual-Doppler and trajectory analysis. The storm they analyzed had several similarities to the case under study herein, notably synoptic and mesoscale settings typical of severe weather in postfrontal upslope flow in the eastern plains of Colorado (Doswell 1980). Their low-level inflow (at $3.5 \mathrm{~km}$ ) was from the southeast into a characteristic reflectivity notch similar to Figs. 3 and 4. Upper-level flow was southwesterly, similar to our case. Conway and Zrnić (1993) also identified a positive $Z_{\mathrm{DR}}$ column slightly offset from the main updraft center, which was nearly collocated with the reflectivity notch, quite similar to Figs. 3 and 4. Their trajectory analysis suggested that particles in the posi- tive $Z_{\mathrm{DR}}$ column originated near $6-\mathrm{km}$ altitude south of the main updraft center, fell cyclonically, and entered the updraft/inflow area. Therefore, they speculated that these recirculated ice particles melted to form the supercooled drops and water-covered ice particles that composed their positive $Z_{\mathrm{DR}}$ column. Trajectories such as described by Conway and Zrnić (1993) appear to be valid in our case also in establishing the positive $Z_{\mathrm{DR}}$ areas in Figs. $3 \mathrm{~b}$ and $4 \mathrm{~b}$. This is further supported by a series of high-resolution RHI scans through the WER discussed next.

\section{b. Vertical sections}

1) Positive $Z_{\mathrm{DR}}$ AReA Below the (UPWIND) REFLECTIVITY OVERHANG AT 1746 MDT

Between 1744 and 1747 MDT, a sequence of constant azimuth $\left(204^{\circ}\right.$ at about 15 -s intervals) RHI scans were taken to study the vertical structure of $Z_{h}$ and $Z_{\mathrm{DR}}$ under the forward (upwind) reflectivity overhang at high spatial resolution. Figure 5 shows the first and last RHI scans from that series at 1744:12 and 1747:15 MDT through the reflectivity notch, the updraft vault, and $Z_{\mathrm{DR}}$ column. Figure 3 a shows the line along which the RHI scan was taken; a white circle locates the range of 30 $\mathrm{km}$ along this line that corresponds to the range axis of Fig. 5. This series of RHI scans is quite interesting in 


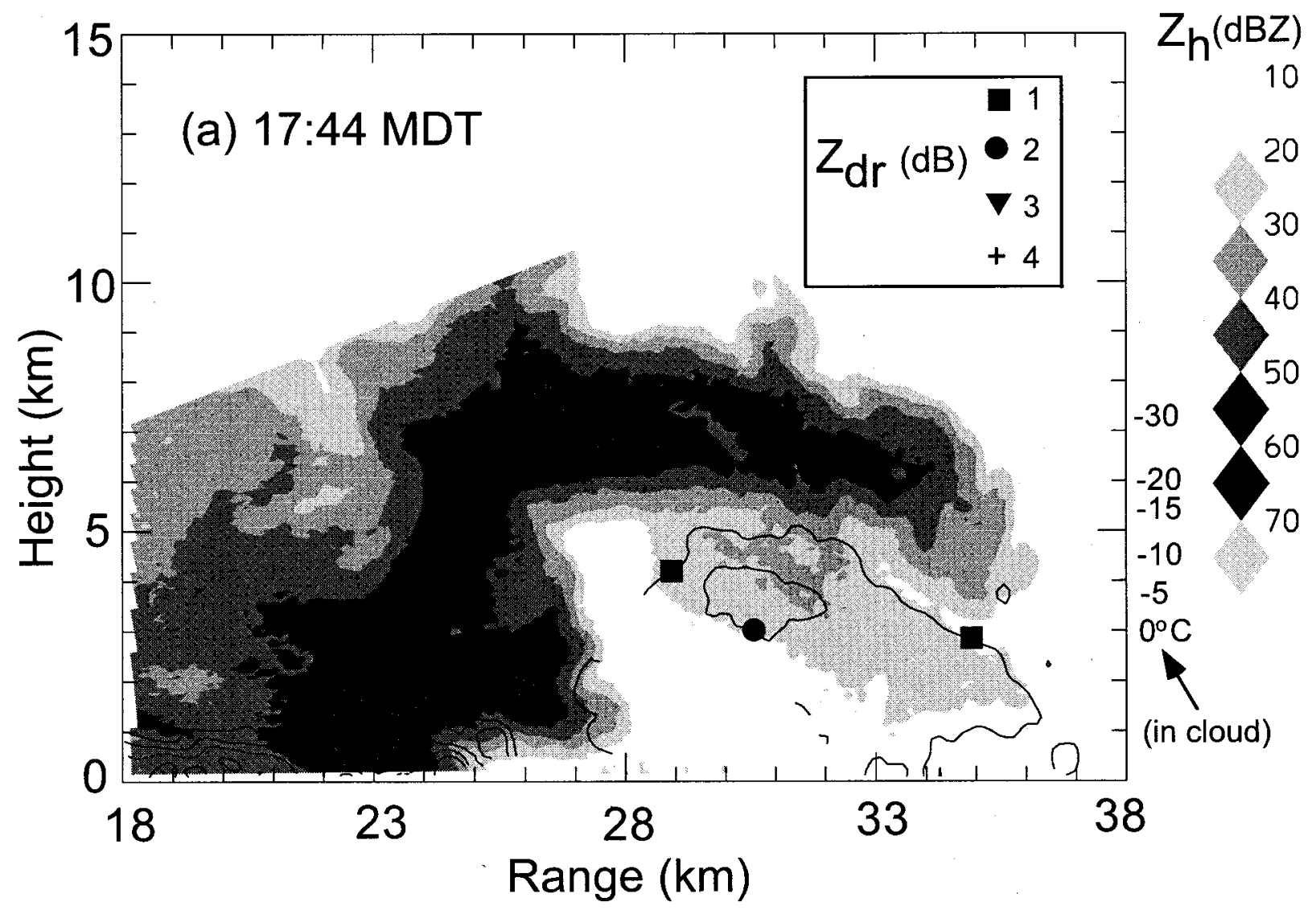

FIG. 5. RHI scans at (a) 1744 MDT and (b) 1747 MDT along the $204^{\circ}$ azimuth direction (see Fig. 3a). Grayscale filled contours of $Z_{h}$ are overlaid with contours of $Z_{\mathrm{DR}}$. The in-cloud temperature scale is based on following a saturated adiabat above the level of free convection.

that an intensification of the positive $Z_{\mathrm{DR}}$ column takes place during this time interval (compare Figs. 2d and 2e; also, the intensification that is more evident from lower-level CAPPIs is not shown). When viewing the RHI scans in sequence, it is easily seen that both the reflectivity and the $Z_{\mathrm{DR}}$ magnitudes increase with time in the area under the reflectivity overhang. The descent of the reflectivity contours from the overhang gives the impression that particles are descending from the reflectivity overhang. Also, the wind vectors from Fig. 3a suggest that some of the descending particles are likely to be captured by the low-level inflow and be advected into the updraft. Thus, $Z_{h}$ and $Z_{\mathrm{DR}}$ fields in Fig. 5, together with the accompanying velocity and convergence fields of Fig. 3, suggest that the drops and water-covered ice particles responsible for the positive $Z_{\mathrm{DR}}$ column originate from the upwind reflectivity overhang. The top of the $Z_{\mathrm{DR}}$ column (3.5-4.5 AGL) also has $\rho_{h v}<0.98$ and enhanced LDR of -20 to $-24 \mathrm{~dB}$ together with positive $Z_{\mathrm{DR}}$. Thus, some of the particles must be oriented to give the positive $Z_{\mathrm{DR}}$, while the enhanced LDR suggests nonspherical tumbling particles are also present. These signatures together indicate a mixed-phase region, that is, supercooled drops, partially frozen (freezing) drops, and frozen particles (Herzegh and Jameson 1992; Conway and Zrnić 1993). For comparison, rain alone would give $\rho_{h v}>0.98$ and LDR $<-25$ dB (Doviak and Zrnić 1993). In appendix E it is shown that such radar signatures can be due to raindrops that are beginning to freeze by developing a thin skin of ice around the liquid core.

For two Montana hailstorms, Miller et al. (1988, 1990), using dual-Doppler and trajectory growth analysis, identified two potential embryo source regions located at low levels $\left(4^{\circ}-10^{\circ} \mathrm{C}\right)$ south and southeast of the main updraft center that could produce large hail. In their case the low-level inflow was from the south or southeast and showed cyclonic curvature as it entered the main updraft area, similar to our case shown in Figs. 3 and 4. They inferred that melted graupel from the forward (upwind) reflectivity overhang, which formed a low-level curtain of drizzle surrounding an area south of the updraft center, was the raindrop embryo source for the large hail grown along that trajectory. Figure 5 clearly shows this curtain of drizzle below the reflectivity overhang (area where $Z_{\mathrm{DR}} \geq 1.0 \mathrm{~dB}$ and below $0^{\circ} \mathrm{C}$ level), and we infer that this region is a likely source of frozen drop embryos. 


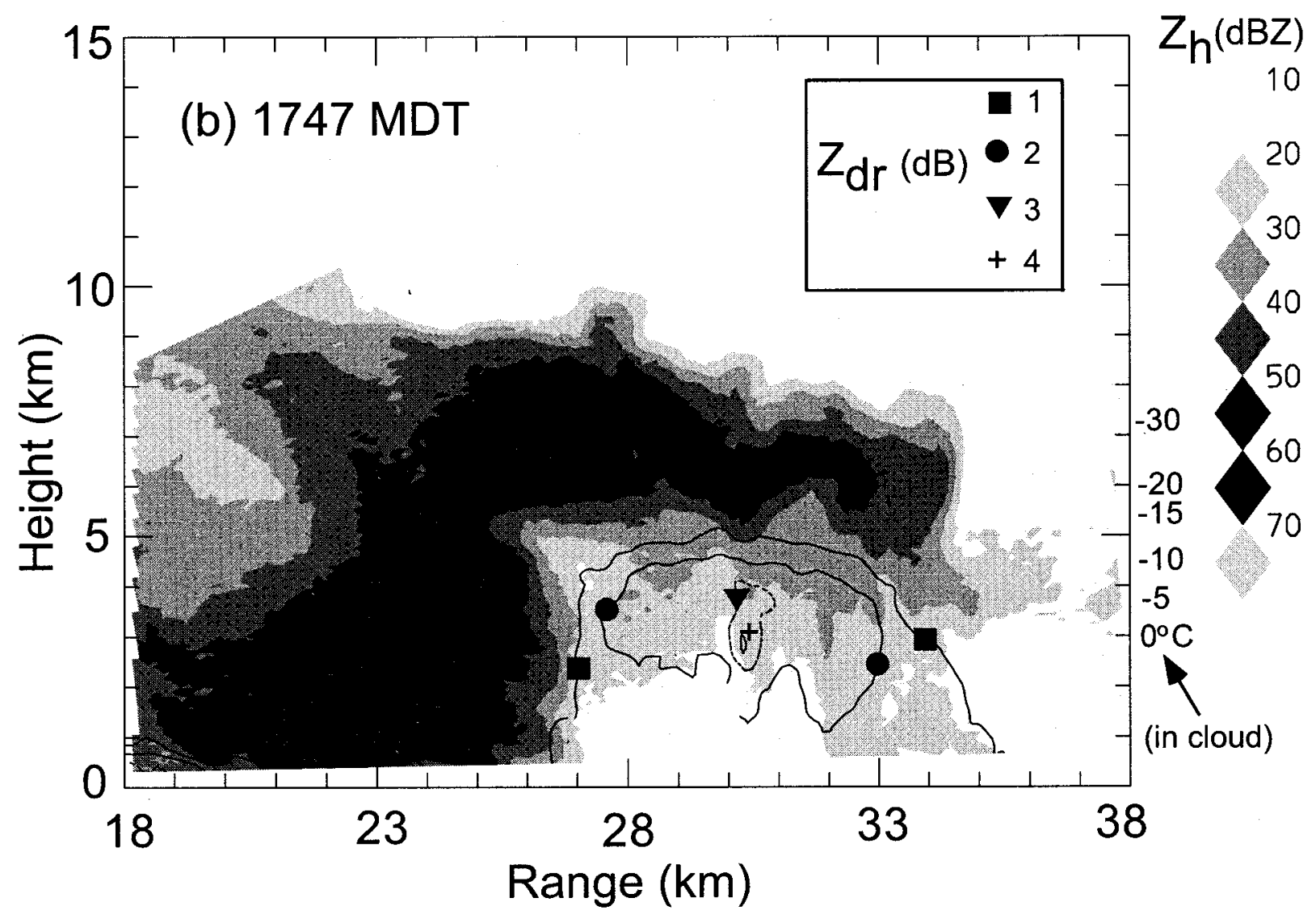

FIG. 5. (Continued)

\section{2) Vertical Sections at 1812 MDT}

Figure 6 shows vertical sections of $Z_{h}, Z_{\mathrm{DR}}$, LDR, $K_{\mathrm{DP}}$, and $\rho_{h v}$, respectively, at 1812 MDT constructed from PPI scan data with vertical resolutions of $0.5-1$ $\mathrm{km}$. The $Z_{h}$ contours are overlaid on the other fields. These sections are taken along a northwest-southeast line marked $\mathrm{AB}$ in Fig. 4b, which is roughly parallel to the low-level inflow direction. By combining the five radar parameters it is possible to identify dominant hydrometeor types in certain areas of the storm using a synthesis of past observations and model scattering calculations (see appendix B for an overview). These areas and hydrometeor characteristics are marked in Fig. 6 and described in greater detail in Table 1 . The following points may be made in describing the hydrometeor types with reference to Fig. 6.

- Large hail falls just west-northwest of the main updraft core.

The area of large wet hail marked as "a" in Fig. 6c (and in Table 1) is characterized by large LDR $(-13$ to $-16 \mathrm{~dB})$ and low $\rho_{h v}(0.88-0.92)$ in association with high $Z_{h}(60-70 \mathrm{dBZ})$ and negative $Z_{\mathrm{DR}}$. The calculations of Aydin and Zhao (1990) support these signatures of large hail. In section 4 , these signatures are also correlated with visual observations of large hail. Traveling from right to left through the storm core marked as regions "a," "b," and "c" in Fig. 6c, the LDR decreases (hail size decreases; also see Table 1). The area of maximum $K_{\mathrm{DP}}$ or rain rate in this plane is marked in Fig. 6d by a "+" and maximum reflectivity in this plane is indicated by an " $\times$." Further to the left, the hail signature disappears, the rain rate decreases to about $30 \mathrm{~mm} \mathrm{~h}^{-1}$ [based on an estimated $K_{\mathrm{DP}}=0.75^{\circ} \mathrm{km}^{-1}$ and $R\left(K_{\mathrm{DP}}\right)=40.5$ $K_{\mathrm{DP}}^{0.85}$ (Chandrasekar et al. 1990)], and the $Z_{\mathrm{DR}}$ increases to $1.5-2.5 \mathrm{~dB}$ (marked "c" in Fig. 6b and Table 1). The graupel melting level is also noted in Fig. 6b, which is marked by the top green contour where 0.5 $<Z_{\mathrm{DR}}<1.0 \mathrm{~dB}$.

- A mix of supercooled raindrops, partially frozen raindrops, and wet graupel are inferred near the top of the positive $Z_{\mathrm{DR}}$ column.

The positive $Z_{\mathrm{DR}}$ column with peak $Z_{\mathrm{DR}}$ of $2.9 \mathrm{~dB}$ at $3.5 \mathrm{~km}$ is located on the inflow side adjacent to the main precipitation shaft marked as " $d$ " in Fig. $6 \mathrm{~b}$ (see also Fig. 4). Using the relationship $10^{-0.1} Z_{\mathrm{DR}}=(a / b)^{7 / 3}$ (Jameson 1983) together with $a / b=1.03-0.62 D_{\text {eq }}$ (where $a / b$ is the axis ratio) and the terminal fall speed versus $D_{\text {eq }}$ for raindrops, the updraft magnitude near the peak $Z_{\mathrm{DR}}$ location is inferred to be sufficient to suspend drops approximately $4.5 \mathrm{~mm}$ in diameter or 

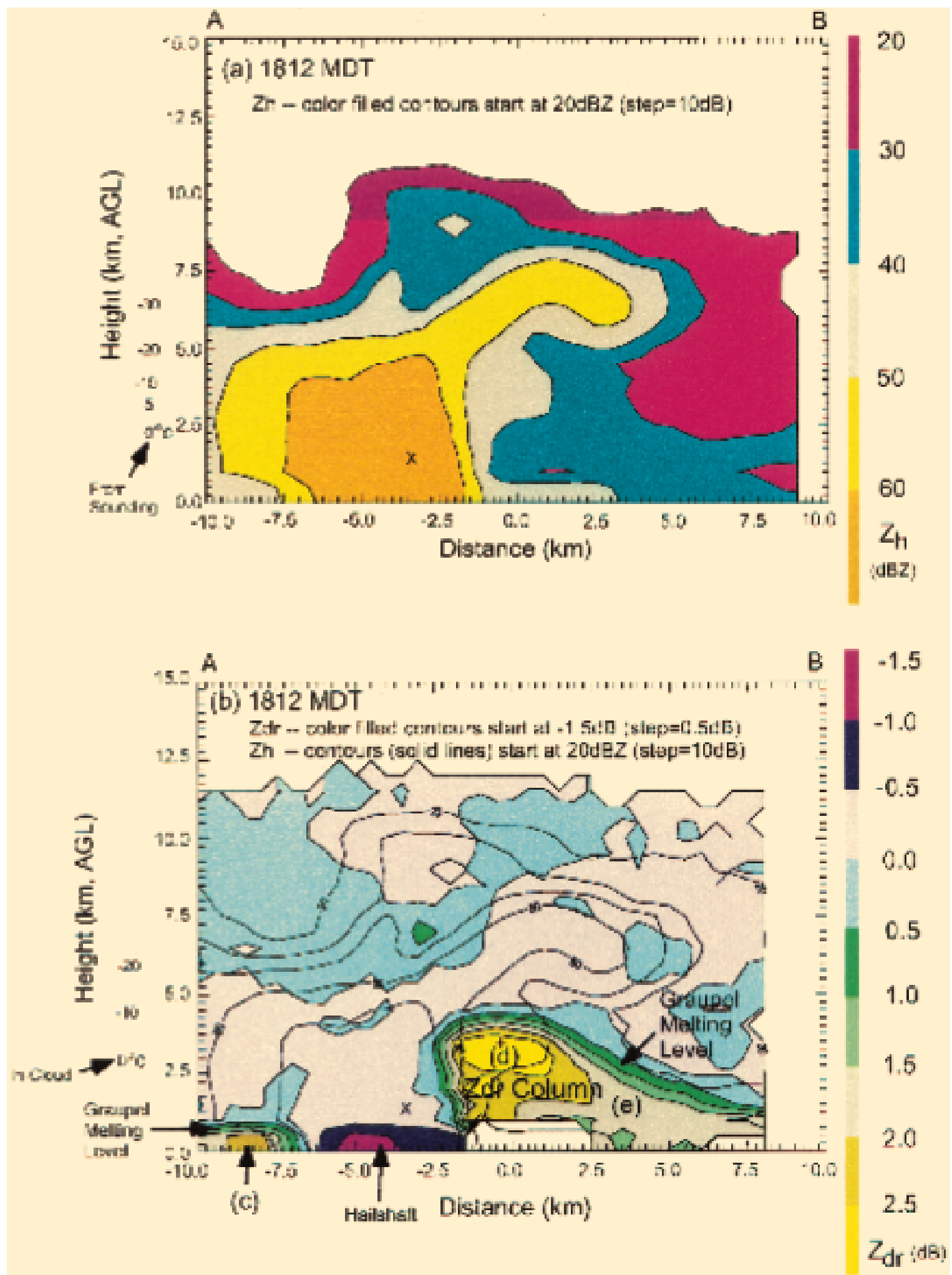

FIG. 6. Vertical sections of multiparameter radar data at 1812 MDT along the line marked A-B shown in Fig. 4b. The new grid origin is at $(-7.7 \mathrm{~km},-21.1 \mathrm{~km})$ relative to the CSU-CHILL location. (a), (c), and (e) The environmental temperature scale was obtained by linearly interpolating between sounding points (Fig. 1b). (b) and (d) The in-cloud temperature scale is as in Fig. 5. Certain interesting features in the radar signatures are marked as locations "a" through "f," which are detailed in Table 1 . The " $X$ " locates the peak $Z_{h}$, while the "+" locates peak values of the relevant variable, that is, $Z_{\mathrm{DR}}$, LDR, $K_{\mathrm{DP}}$, or $\rho_{h v}$ in (b)-(e). 


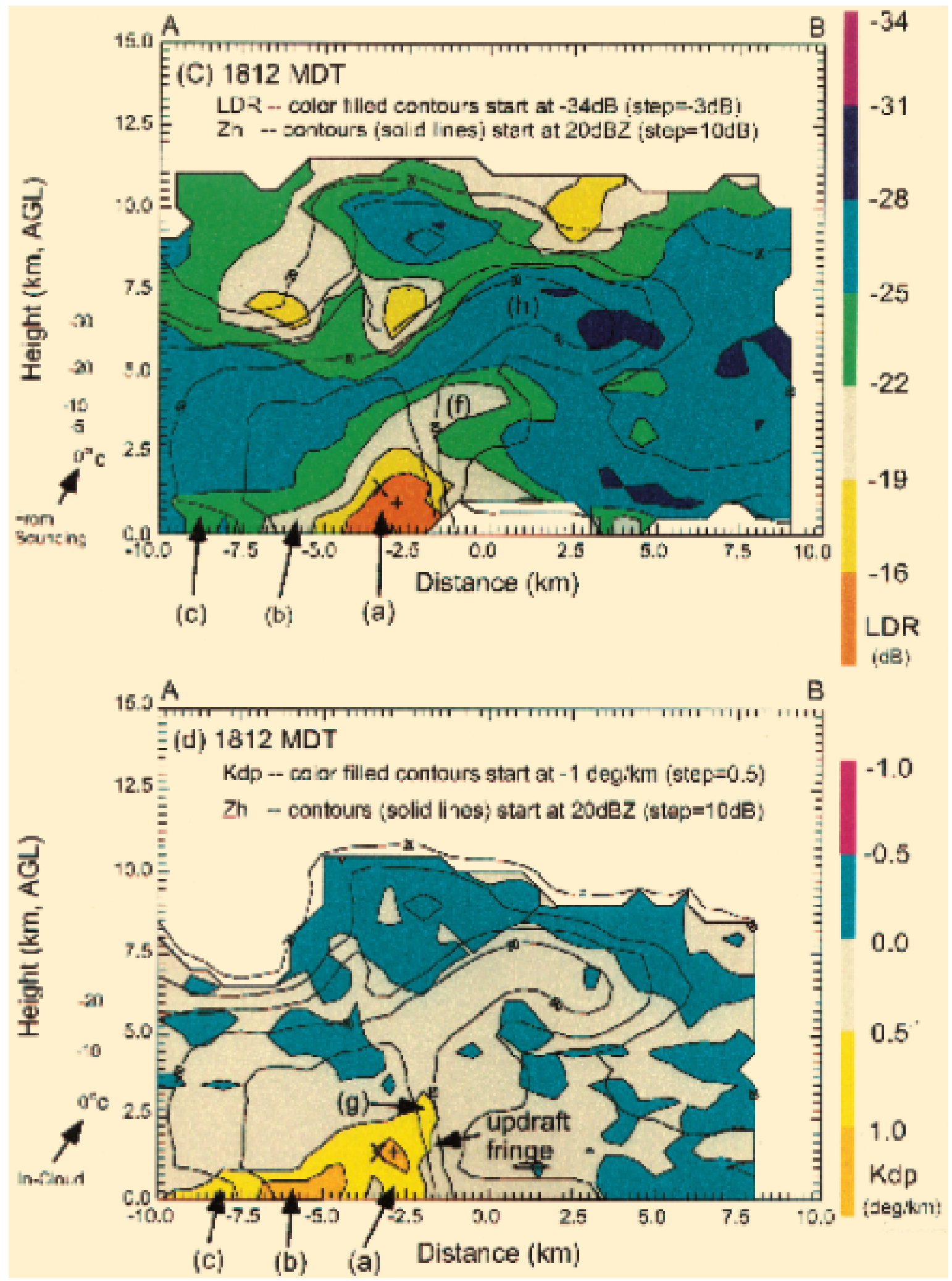

FIG. 6. (Continued) 


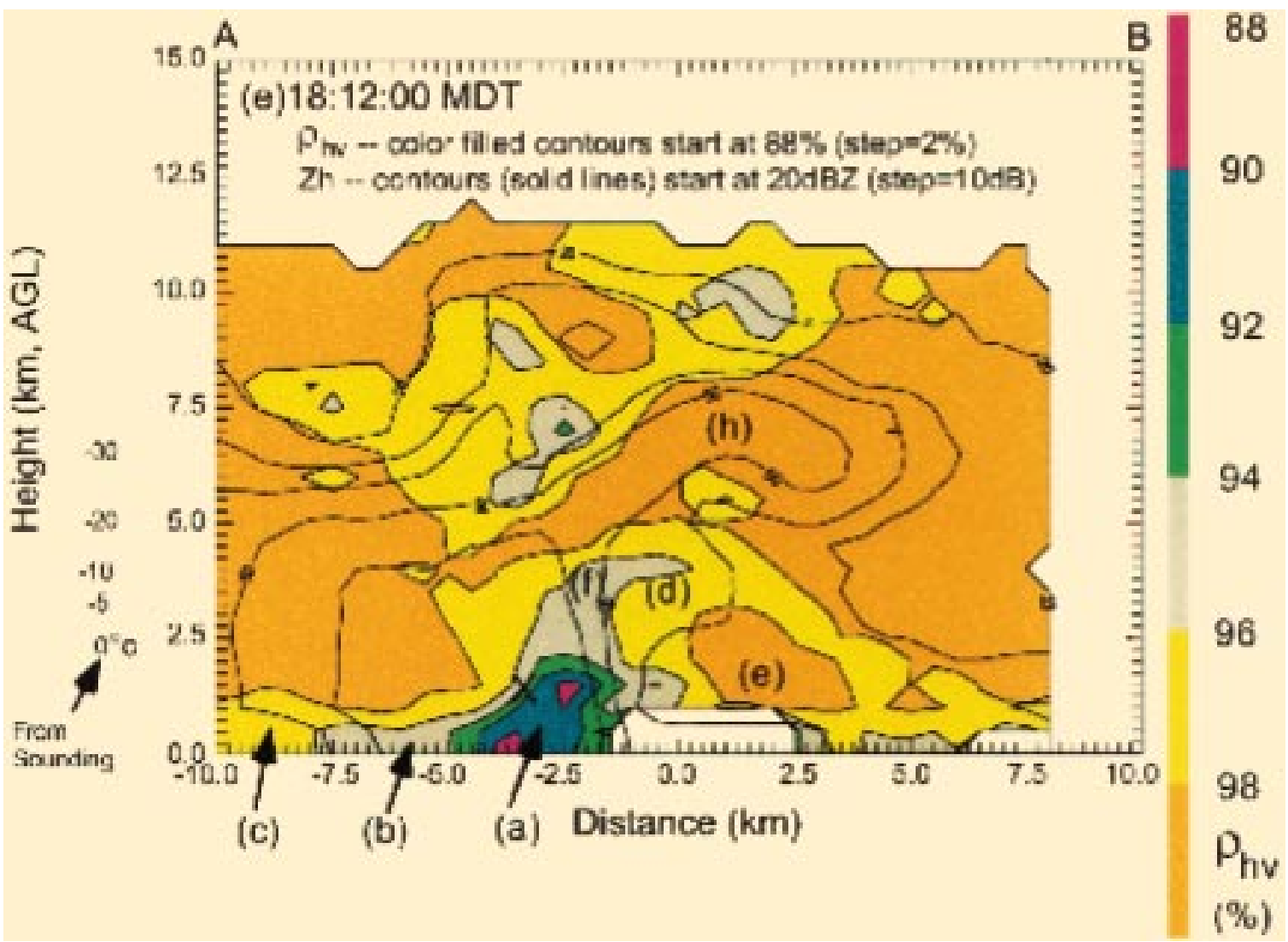

FIG. 6. (Continued)

about $9 \mathrm{~m} \mathrm{~s}^{-1}$. At lower altitudes $(2 \mathrm{~km})$ within the column, raindrops are inferred with diameters of 2.5$3.5 \mathrm{~mm}$ (assuming a monodisperse size distribution) at concentrations significantly lower than MarshallPalmer (1948) values at the same $Z_{h}(30-40 \mathrm{dBZ})$. This region is marked as " $\mathrm{e}$ " in Fig. 6b. The top of the column (1-dB contour) slopes downward with distance away from the peak $Z_{\mathrm{DR}}$ (east-southeastward), corresponding to weakening updrafts in this plane.
In Fig. 6c, a region of $\mathrm{LDR} \geq-22 \mathrm{~dB}$ (marked as " $f$ ") is coincident with the top of the positive $Z_{\mathrm{DR}}$ column, where $Z_{h}$ is $40-50 \mathrm{dBZ}$. This LDR “cap" is nearly coincident with a similar low $\rho_{h v}$ cap shown in Fig. 6e (marked as "f"). For particles whose symmetry axis are randomly oriented in the polarization plane, it can be shown that $\rho_{h v}$ is related to LDR through $\rho_{h v}=1-2\left(10^{0.1 \mathrm{LDR}}\right)$ (Mead et al. 1991). This condition is generally met when the elevation angle

TABLE 1. The radar signatures for the seven regions in Fig. 6.

\begin{tabular}{|c|c|c|c|c|c|}
\hline Storm region & $Z_{h}(\mathrm{dBZ})$ & $Z_{\mathrm{DR}}(\mathrm{dB})$ & $\mathrm{LDR}(\mathrm{dB})$ & $K_{\mathrm{DP}}\left(\operatorname{deg} \mathrm{km}^{-1}\right)$ & $\rho_{h v}(\%)$ \\
\hline $\begin{array}{l}\text { (a) Large hail mixed with rain } \\
\text { near surface }\end{array}$ & $60-70$ & $(-1.5)-0$ & $(-13)-(-19)$ & $0-1$ & $88-92$ \\
\hline $\begin{array}{l}\text { (b) Small-/medium-sized hail } \\
\text { mixed with rain near sur- } \\
\text { face }\end{array}$ & $50-70$ & $(-1.5)-1$ & $(-16)-(-22)$ & $1-1.5$ & $94-96$ \\
\hline $\begin{array}{l}\text { (c) Rain with wet graupel at } \\
\text { surface }\end{array}$ & $40-50$ & $1.5-2.5$ & $(-22)-(-25)$ & $0.5-1$ & $96-98$ \\
\hline $\begin{array}{l}\text { (d) Positive } Z_{\mathrm{DR}} \text { column near } \\
\max Z_{\mathrm{DR}}\end{array}$ & $30-50$ & $1.5-3.0$ & $(-19)-(-25)$ & 0 & $96-98$ \\
\hline $\begin{array}{l}\text { (g) Positive } K_{\mathrm{DP}} \text { column near } \\
2.5 \mathrm{~km} \text { AGL }\end{array}$ & $50-60$ & $0-2.0$ & $(-16)-(-22)$ & $0.5-1.5$ & $94-96$ \\
\hline $\begin{array}{l}\text { (h) Forward reflectivity over- } \\
\text { hang }\end{array}$ & $50-60$ & $(-0.5)-0.5$ & $(-25)-(-28)$ & 0 & $98-100$ \\
\hline (f) LDR cap at altitudes $\geq 2 \mathrm{~km}$ & $40-60$ & $0-2$ & $(-19)-(-25)$ & $0-1$ & $92-96$ \\
\hline
\end{tabular}


is $90^{\circ}$ (vertical incidence), for example, observations of the bright band. Deviations from this relation enabled Galloway et al. (1997) to infer ice particle alignment using radar measurements at $95 \mathrm{GHz}$. The correlation between LDR and $\rho_{h v}$ signatures in Figs. $6 \mathrm{c}$ and $6 e$ reflects the general tendency exhibited by random orientation in the polarization plane expected for hailstones. However, the mix of raindrops with hailstones below the melting level complicates the relationship between LDR and $\rho_{h v}$ (see also Jameson et al. 1996). The combination of radar measurements in this region listed in Table 1 is consistent with a mix of supercooled drops, partially freezing drops, and asymmetric wet graupel (Herzegh and Jameson 1992; Conway and Zrnić 1993; Jameson et al. 1996). In appendix E, model scattering calculations from partially freezing drops are described that are consistent with the radar measurements in this region. Bringi et al. (1997) also provide in situ verification of this signature using penetrating aircraft data in a Florida thunderstorm.

- Drops shed by wet hailstones are inferred on the western fringe of the main updraft.

The vertical structure of $K_{\mathrm{DP}}$ in Fig. 6d shows a positive $\left(0.5^{\circ}-1^{\circ} \mathrm{km}^{-1}\right)$ column (marked as " $\mathrm{g}$ ") that lies within the $50-\mathrm{dBZ}$ contour. It is coincident with LDR $\geq-22 \mathrm{~dB}$ and is located near the interface between the main hailshaft and the positive $Z_{\mathrm{DR}}$ column (this interface is marked as "updraft fringe" in Fig. $6 \mathrm{~d}$ ). The positive $K_{\mathrm{DP}}$ area is also clearly seen in Fig. $4 \mathrm{c}$ on the western fringe of the area of maximum horizontal convergence. It is hypothesized that the positive $K_{\mathrm{DP}}$ column is caused by drops shed from wet hailstones that are either melting or in wet growth (Lesins et al. 1980; Joe and List 1984; Rasmussen and Heymsfield 1987a) and are falling through the updraft fringe, which cannot support the hail but can loft the shed drops. Shed drops are likely to be as large as 2 $\mathrm{mm}$ (with the mode around $1 \mathrm{~mm}$ ), which in sufficient concentrations can easily yield $K_{\mathrm{DP}}$ in the range $0.5^{\circ}-$ $1.5^{\circ} \mathrm{km}^{-1}$ (Joe and List 1984). It is likely that wet hail is falling within the positive $K_{\mathrm{DP}}$ column since LDR is large $(-19$ to $-22 \mathrm{~dB}), \rho_{h v}$ is low $(94 \%-$ 96\%), and large hail was confirmed at ground in this general area. Table 1 lists the radar values under $g$; note the positive $Z_{\mathrm{DR}}$ values between 0 and $2 \mathrm{~dB}$ along the western updraft fringe overlapping with the positive $K_{\mathrm{DP}}$ column and, thus, it is possible that these shed water drops also contribute to the positive $Z_{\mathrm{DR}}$ column signature at least in this area. Rasmussen and Heymsfield (1987b) found from T-28 aircraft data in a Montana supercell storm (the same one discussed by Miller et al. 1990) that millimeter-sized drops were collocated with hailstones in the updraft core and fringe areas. They also showed that shed drops can be an important source for hailstone embryos. The location of shed drops, inferred from the positive $K_{\mathrm{DP}}$ column in the west fringe of the updraft (see Figs. $4 \mathrm{c}$

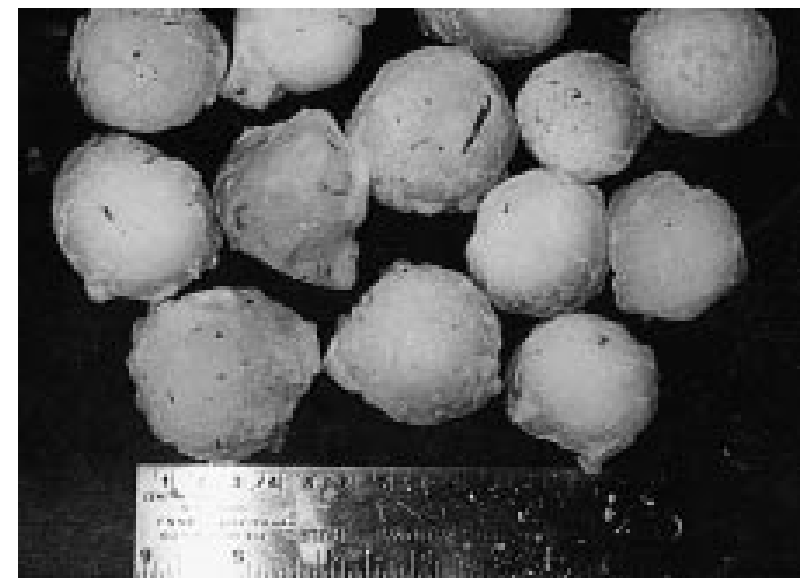

FIG. 7. A sample of the largest hailstones collected after the storm cell passed over the chase van location marked by " $X$ " in Figs. 3b and $4 \mathrm{~b} ; D_{\max }$ is approximately $5 \mathrm{~cm}$.

and 6d), places them in a favorable location for growth into large hail, which is consistent with the trajectory growth calculations of Rasmussen and Heymsfield (1987b). This $K_{\mathrm{DP}}$ column signature was persistent during the intense phase of the storm.

- Graupel/low density hail dominates in the reflectivity overhang.

The overhang with $Z_{h}$ in the range $50-60 \mathrm{dBZ}$ is marked as "h" in Fig. 6e. Table 1 lists the radar parameters; the LDR values $(-25$ to $-28 \mathrm{~dB})$ and high $\rho_{h v}$ are consistent with graupel/low density hail. Graupel particles are inferred below the overhang and eastsoutheast of the LDR cap. Pockets of low $\rho_{h v}$ and enhanced LDR above $5 \mathrm{~km}$ (see Figs. 6c and 6e) are due to three-body scattering (Zrnić 1987) and errors caused by gradients in the reflectivity (see appendix C) and thus they are not physically meaningful.

\section{c. Frozen drop embryos and large hail production}

Thin section analysis of 20 of the largest $(D>30$ $\mathrm{mm}$, see Fig. 7) hailstones gathered after the storm core had passed over the chase van suggests that five stones had drop embryos, two stones likely had drop embryos, three stones were fragmented with unidentified embryos, and the rest likely had graupel embryos. Thus, between $30 \%$ and $40 \%$ of the large stones likely had drop embryos. As described in the next section, time-resolved hail size distributions were estimated between 1803 and 1809 MDT, during which hailstones were collected using the roof-mounted net system. These hailstones were classified into two size categories: $D<2 \mathrm{~cm}$ and $D \geq$ $2 \mathrm{~cm}$. Thin section analysis revealed that $23 \%-33 \%$ of the stones with $D \geq 2 \mathrm{~cm}$ had drop embryos, while for $D<2 \mathrm{~cm}, 10 \%-15 \%$ had drop embryos. These results are comparable to the climatology of hailstone embryos from northeastern Colorado by Knight (1981). Figure 8 shows thin sections of two of the large hailstones il- 

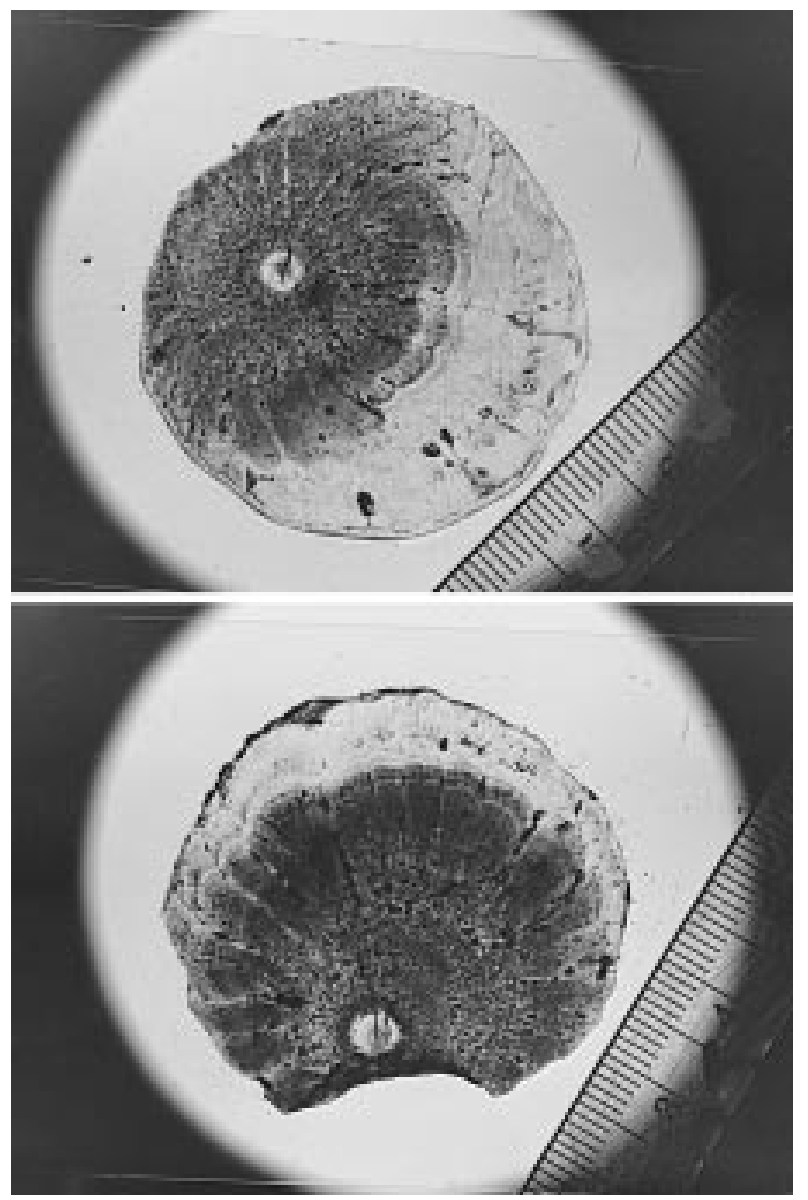

FIG. 8. Thin sections of two large hailstones collected after the storm cell passed over the chase van. Inset scale shows centimeter marks. Note the raindrop embryos and the final one-sided growth pattern indicating possible preferential alignment of the hailstone.

luminated by ordinary light that were collected (scale is in centimeters). Note the well-defined drop embryos that are offset from the stones' center with cracks likely due to drop freezing (Knight and Knight 1970). The clear areas in Fig. 8 correspond to wet growth layers, while the opaque areas correspond to dry growth (Macklin 1977).

One method of inferring the possible relationship of the positive $Z_{\mathrm{DR}}$ column to large hail production is to plot swaths of the various radar measurands over time. Figure 9 a shows a swath of LDR $\geq-20 \mathrm{~dB}$ at the $0.5-\mathrm{km}$ level, (solid lines) constrained by $Z_{h}>55$ $\mathrm{dBZ}, Z_{\mathrm{DR}}<0.5 \mathrm{~dB}$, and $\rho_{h v}<0.95$, overlaid with the swath of $Z_{\mathrm{DR}}>1.0 \mathrm{~dB}$ at the $3.5-\mathrm{km}$ level (dashed lines) for 1720-1833 MDT. Both LDR and $Z_{\mathrm{DR}}$ swaths were created by selecting at each grid point the maximum value from all analyzed volumes. The positive $Z_{\mathrm{DR}}$ swath is located southeast of the large hail swath and is considered here as a potential frozen drop embryo source region. The location of the positive $Z_{\mathrm{DR}}$ swath across the main inflow region places the em- bryos in a favorable position for the production of large hail, which is in general agreement with the trajectory analyses of Conway and Zrnić (1993) and Miller et al. (1988, 1990).

Figure $9 \mathrm{~b}$ shows a swath of the LDR $>-25 \mathrm{~dB}$ cap region at $4.5-\mathrm{km}$ altitude (dashed lines) for $30 \mathrm{dBZ}<$ $Z_{h}<50 \mathrm{dBZ}$ and $Z_{\mathrm{DR}}>0.5 \mathrm{~dB}$. This swath is entirely contained within the positive $Z_{\mathrm{DR}}$ swath and marks an interface region $\left(-5^{\circ}\right.$ to $\left.-15^{\circ} \mathrm{C}\right)$ composed of a mix of supercooled drops, partially freezing drops, and asymmetric wet graupel. Figure $9 \mathrm{~b}$ also shows the swath of $K_{\mathrm{DP}}>0.5^{\circ} \mathrm{km}^{-1}$ at $2.5-\mathrm{km}$ altitude (solid lines) constrained by $Z_{h}>50 \mathrm{dBZ}$. This swath is located generally between the large hailswath and the positive $Z_{\mathrm{DR}}$ swath, that is, along the low-level updraft/downdraft interface. If our inference that the positive $K_{\mathrm{DP}}$ at this level is due to millimeter-sized drops being shed by wet hail is true, then these raindrops are in a favorable region to be carried aloft, freeze, and become embryos for large hail, as described by Rasmussen and Heymsfield (1987b) and Miller et al. (1988).

Figure $9 \mathrm{c}$ shows a swath of $\mathrm{LDR} \geq-25 \mathrm{~dB}$ at 4.5 $\mathrm{km}$ altitude (solid lines) constrained by $Z_{h}>55 \mathrm{dBZ}$ overlaid with the LDR cap swath of Fig. 9b. Enhanced LDR $(>-25 \mathrm{~dB})$ accompanied with large reflectivities could indicate wet growth, for example, the outer clear layers of the hailstones shown in Fig. 8. The region where this signature exists is below the estimated $-20^{\circ} \mathrm{C}$ in cloud altitude, which is considered to be a rough border separating wet growth and dry growth regions (Macklin 1977). More accurately, the type of growth regime (wet versus dry) is dependent not only on liquid water content (LWC) of the air and ambient temperature but also on the size of the ice particle. The larger the ice particle, the lower the LWC required to place the particle in the wet growth regime. Based on a heat balance equation, a line can be plotted for a particular size ice particle as a function of LWC and ambient temperature that separates wet and dry growth regimes (see Fig. 8.6 of Young 1993) and is referred to as the Schumann-Ludlam limit. From the larger hailstones collected in the present case, the opaque centers had diameters of about $3 \mathrm{~cm}$. According to the SchumannLudlam limit, for temperatures between $-10^{\circ}$ and $-20^{\circ} \mathrm{C}$, LWC greater than 1 to $1.75 \mathrm{~g} \mathrm{~m}^{-3}$, respectively, are needed to place the hailstones in the wet growth regime, which is easily realizable in such severe storms (Knight et al. 1982). Additionally, modeling studies show that low density graupel and small dry hail typically have LDR $<-25 \mathrm{~dB}$ and wet ice hydometerors typically have more elevated LDR signatures (Aydin and Zhao 1990; Doviak and Zrnić 1993). At higher altitudes within the high-reflectivity region, LDR decreases (see Fig. 6c) to less than $-25 \mathrm{~dB}$. The locations of enhanced LDR at midlevels corresponding to wet hail and the LDR cap at the top of the positive $Z_{\mathrm{DR}}$ column appear to be consistent with the hail trajectories that originate at midlevels southeast of the updraft core pass 

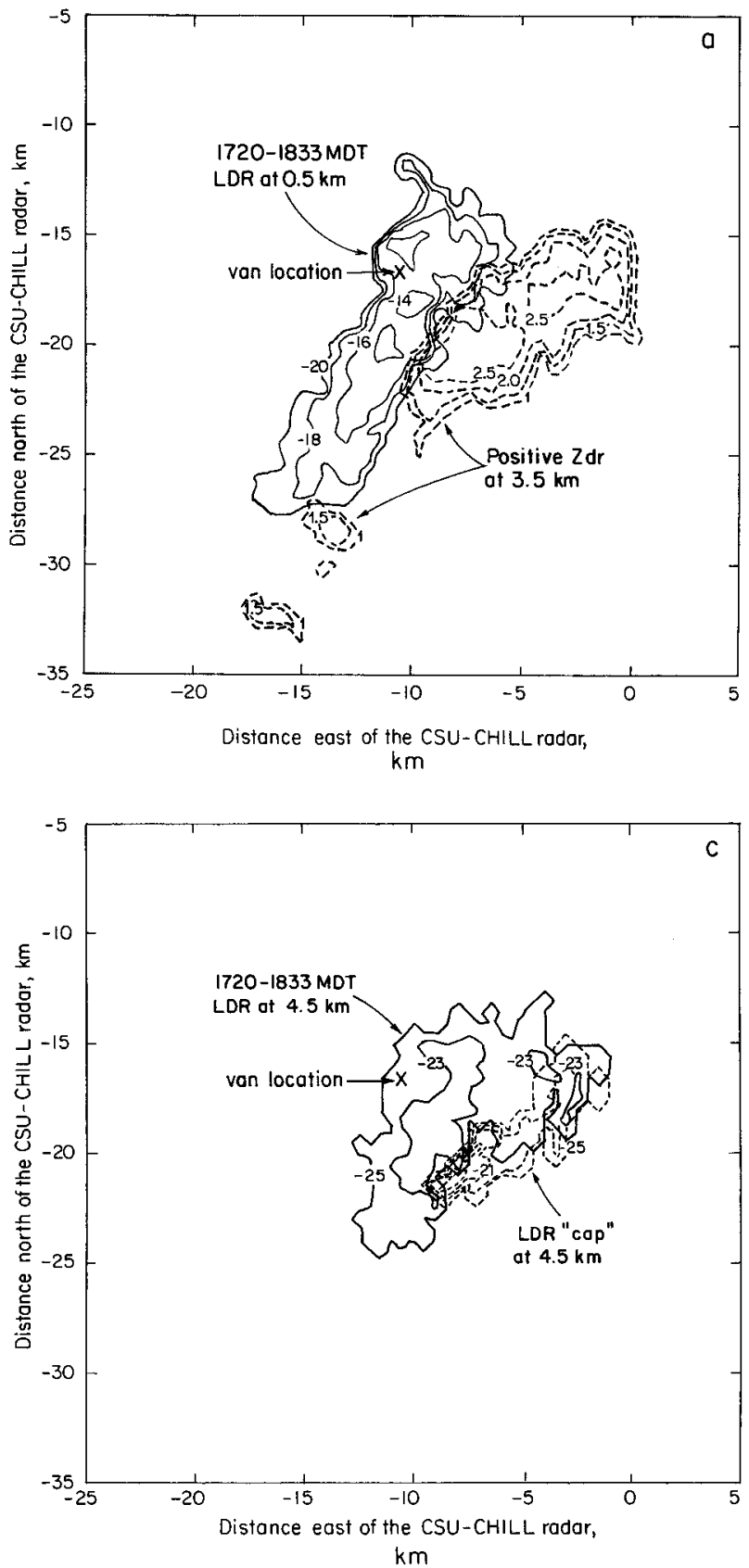

through the LDR cap rising to heights of about $7 \mathrm{~km}$ (around $-30^{\circ} \mathrm{C}$ ), where it is likely that dry growth (e.g., the opaque inner layers of the hailstones shown in Fig. 8 ) takes place. According to the Schumann-Ludlam limit, for temperatures between $-25^{\circ}$ and $-30^{\circ} \mathrm{C}$, LWC greater than 3.2 to $4.1 \mathrm{~g} \mathrm{~m}^{-3}$, respectively, are needed to place $2-\mathrm{cm}$ hailstones in the wet growth regime. In the mean, LWCs for severe Colorado hailstorms are typically much less than the adiabatic LWCs (LWCA) due to depletion by cloud ice and dilution by entrainment [(e.g., mean LWC/LWCA $=63 \%$; Knight et al.

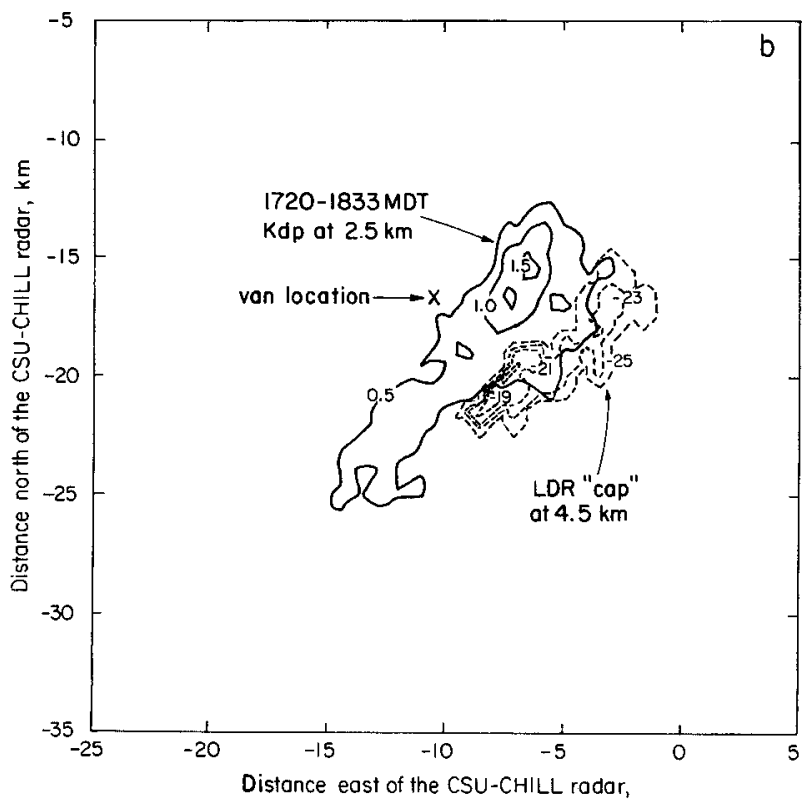

$\mathrm{km}$

FIG. 9. Swaths of radar signatures from 1720 to 1835 MDT. (a) LDR $>-20 \mathrm{~dB}$ (solid lines) at $0.5-\mathrm{km}$ level constrained by $Z_{h}>$ $55 \mathrm{dBZ}, Z_{\mathrm{DR}}<0.5 \mathrm{~dB}$, and $\rho_{h v}<0.95$. It represents the surface hailswath. Dashed lines are swaths of $Z_{\mathrm{DR}}>1.0 \mathrm{~dB}$ at $3.5 \mathrm{~km}$ AGL representing the positive $Z_{\mathrm{DR}}$ column location, which marks, in part, the low-level updraft. (b) Swath of $K_{\mathrm{DP}}>0.5^{\circ} \mathrm{km}^{-1}$ at $2.5 \mathrm{~km}$ AGL (solid lines) constrained by $Z_{h}>55 \mathrm{dBZ}$. It represents the swath of drops shed by wet hail. Dashed lines show swath of LDR cap where LDR $>-25 \mathrm{~dB}$ at $4.5 \mathrm{~km}$ AGL constrained by $30<Z_{h}<50 \mathrm{dBZ}$ and $Z_{\mathrm{DR}}>0.5 \mathrm{~dB}$. It maps the mixed-phase interface region. (c) Swath of LDR $>-25 \mathrm{~dB}$ at $4.5 \mathrm{~km}$ constrained by $Z_{h}>55 \mathrm{dBZ}$. It represents the hailswath at midlevels where the hail is likely experiencing wet/spongy growth. Dashed lines are the same as in (b).

(1982)]. Since the LWCs above are $75 \%-91 \%$ of the LWCA at these temperatures (4.25 to $4.5 \mathrm{~g} \mathrm{~m}^{-3}$ ), it is unlikely that wet growth was achieved at temperatures colder than $-25^{\circ} \mathrm{C}$, which is consistent with the discussion above. The trajectory then likely drops downward along the hail cascade perhaps undergoing wet growth at midlevels (4-5 km), as marked by the enhanced LDR signature discussed above. Similar hail trajectories have been described by Conway and Zrnić (1993) (see their Fig. 17), which led to the largest $(\approx$ $6 \mathrm{~cm}$ ) hail at the surface in their supercell study. They 
(a)

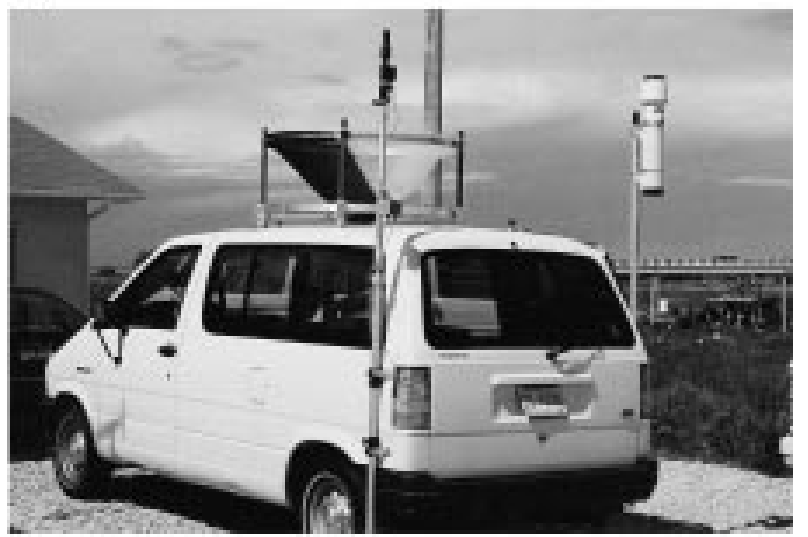

(b)

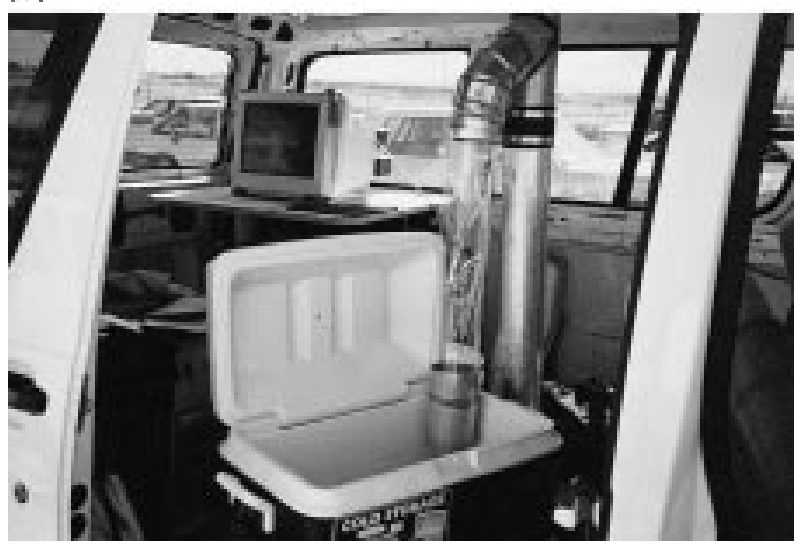

FIG. 10. (a) Picture of the hail chase van with roof-mounted hail "catcher" net (obtained from National Center for Atmospheric Research, courtesy of N. Knight). The Young capacitance rain gauge is on a pole mount on the right, rear side of the van. (b) Close-up view of the rain/hail separator mechanism. The "flexible" plastic tube routes the hailstones into a jar of cold hexane (packed in dry ice). The center tube directs rain to an opening in the van floor.

also found a preponderance of frozen drop embryos within a sample of large hailstones collected near the region predicted by the end points of their trajectories. Miller et al. (1990) also analyzed "straight line" trajectories that led to the largest hail in their hailstorm (see their Fig. 21), which are similar to those hypothesized here.

\section{Surface measurements}

A hail chase van with a roof-mounted net obtained from the National Center for Atmospheric Research (NCAR) was used to intercept the storm core. On 7 June 1995, the van was directed to a location $(-10.25$, $-16.75 \mathrm{~km}$ ) marked by an " $x$ " in Figs. $3 b$ and $4 b$. The van was in position ahead of the storm core (i.e., to its northeast) at 1740 MDT. Figure 10 shows a picture of the chase van and a close-up view of the rain/hail separator mechanism. Hail was collected and quenched in chilled hexane and then stored in dry ice (Knight 1981).
A Young capacitance rain gauge was also installed in the van and interfaced to a personal computer that recorded rainfall amounts every few seconds. In this particular event, manual hail collection was possible only for about $5 \mathrm{~min}$, from 1803 to 1808 MDT, before the severity of the hailfall pulled the netting from the circular frame. Radar measurements over the van location are shown in Figs. 11a-d. The last panel shows gauge rainfall accumulation compared with accumulations computed from $R\left(K_{\mathrm{DP}}\right)=40.5 K_{\mathrm{DP}}^{0.85}$ and $Z_{h}=300 R^{1.4}$ (truncated at $55 \mathrm{dBZ}$ ). The $K_{\mathrm{DP}}$ relationship is from Chandrasekar et al. (1990), while the $Z-R$ relation is used by NEXRAD (Kelsh 1989). Except for LDR, the other radar variables were averaged over a circular area of diameter of $1 \mathrm{~km}$ centered over the van. The LDR values from a single range resolution volume over the van were used to avoid data contamination due to low signal-to-noise ratio, reflectivity gradients, and threebody scattering. Visual observations of hail size made by two of the authors (VNB and $\mathrm{JH}$ ) in the van are marked in Fig. 11c. The time period 1803-1808 MDT, during which hail collection using the roof-mounted net was possible, is marked by solid triangles. The following points are made with reference to Fig. 11.

1) Rainfall accumulation using $K_{\mathrm{DP}}$ is in excellent agreement with gauge data.

Several studies have shown the advantage of $K_{\mathrm{DP}}$ in rainfall estimation in the presence of hail (Aydin et al. 1995; Zrnić and Ryzhkov 1996; Balakrishnan and Zrnić 1990a). This particular comparison is perhaps unique because of the severity of the hailfall and the duration of the event. Both gauge and $R\left(K_{\mathrm{DP}}\right)$ methods gave a total rainfall accumulation of $40 \mathrm{~mm}$, while $R\left(Z_{h}\right)$, in spite of truncation at $55 \mathrm{dBZ}(144 \mathrm{~mm}$ $\mathrm{h}^{-1}$ ), overestimates the total accumulation by a factor of 2. As noted by Aydin et al. (1995), the truncation point will depend on hail rate and maximum hail size and could vary from storm to storm. Even though the maximum $K_{\mathrm{DP}}$ over the van location was around $2.5^{\circ} \mathrm{km}^{-1}$ (see Fig. $11 \mathrm{~b}$ at $1000 \mathrm{~s}$ or 1809 : $40 \mathrm{MDT}$ ), the maximum $K_{\mathrm{DP}}$ at 1812 was around $4.5^{\circ} \mathrm{km}^{-1}\left(145 \mathrm{~mm} \mathrm{~h}^{-1}\right)$ about $2 \mathrm{~km}$ to the northwest of the van location (see Fig. $4 \mathrm{~b}$ for van location).

2) The period of large (golfball sized) hail is easily identified by negative $Z_{\mathrm{DR}}$, low $\rho_{h v}$, and high LDR.

Visual observations of golfball-sized hailfall (see Fig. 7 for a sample of the largest hail) started around 1809 (1000 s in Fig. 11c) and ended around 1827 MDT $(2000 \mathrm{~s})$. The occurrence of negative $Z_{\mathrm{DR}}$ is frequently observed in hailstorms (Husson and Pointin 1989; Aydin et al. 1990; Zrnić et al. 1993) with large hail and is also noted over the van between 1200 and $2000 \mathrm{~s}$, where $Z_{\mathrm{DR}} \leq-0.5 \mathrm{~dB}$. Low $\rho_{h v}$ $(\leq 0.93)$ and high LDR $(\geq-18 \mathrm{~dB})$ between 1080 and $1750 \mathrm{~s}$ (1811-1821 MDT) also correlate well with golfball-sized hail. Earlier studies have shown the lowering in $\rho_{h v}$ in rain mixed with hail or in large 

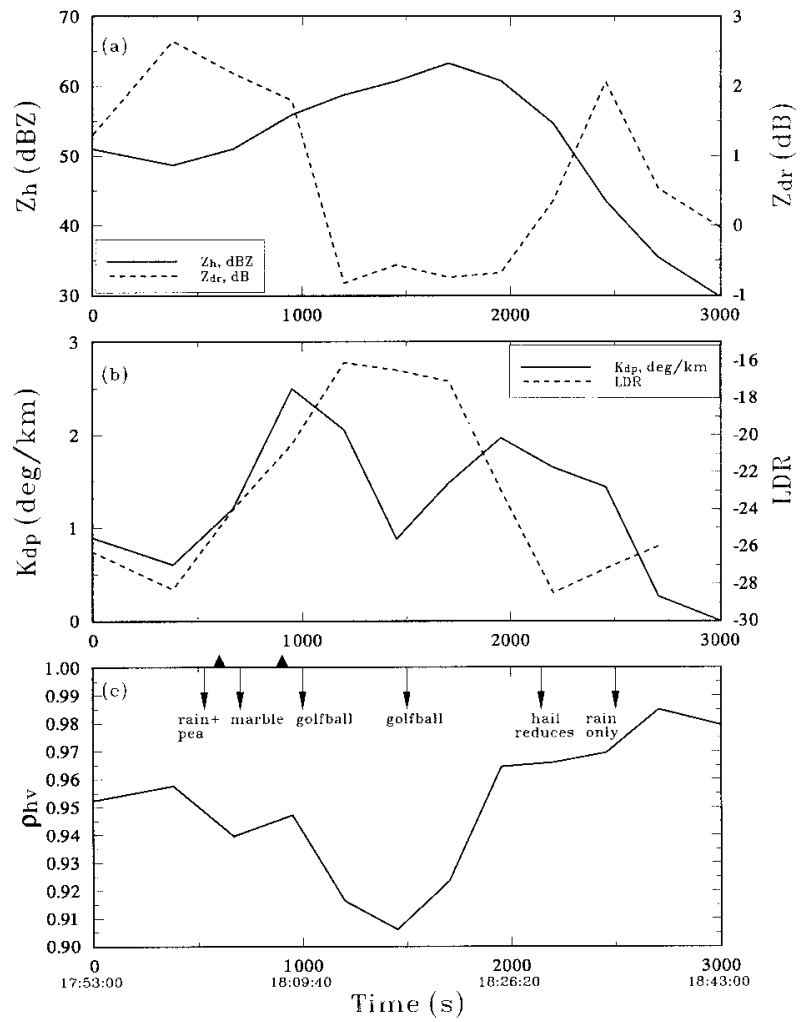

asymmetric hail with surface lobes (Balakrishnan and Zrnić 1990b; Zrnić et al. 1993). Aydin and Zhao (1990) used an exponential hail size distribution (Cheng and English 1983) with $D_{\max }=5 \mathrm{~cm}$ together with the melting model of Rasmussen and Heyms-

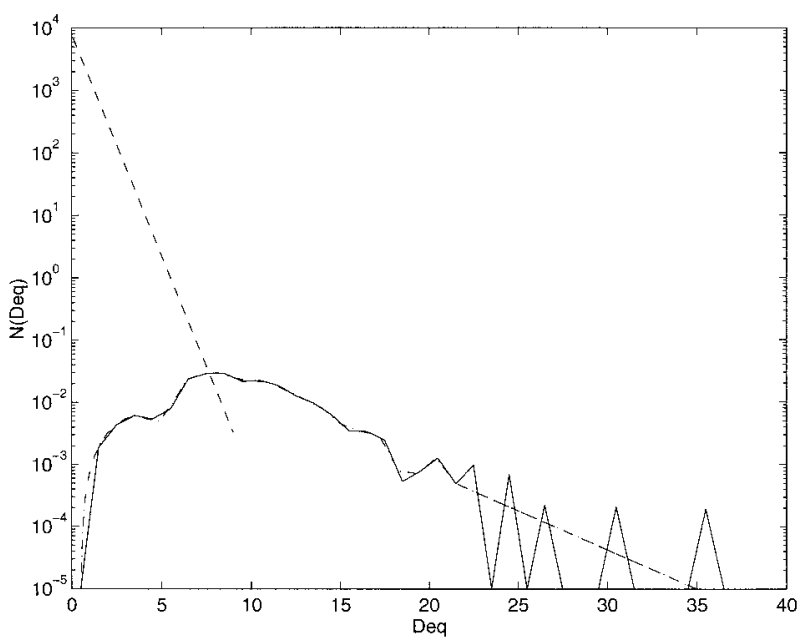

FIG. 12. Hailstone size distribution (solid line) calculated from hail collected with the roof mounted netting system from 1803 to 1808 MDT. The dashed-dotted line shows the interpolated fit to the distribution. The dashed line is the Marshall-Palmer (1948) raindrop size distribution for a rain rate of $80 \mathrm{~mm} \mathrm{~h}^{-1}$ (based on $K_{\mathrm{DP}} \approx 2.5^{\circ}$ $\mathrm{km}^{-1}$ ).

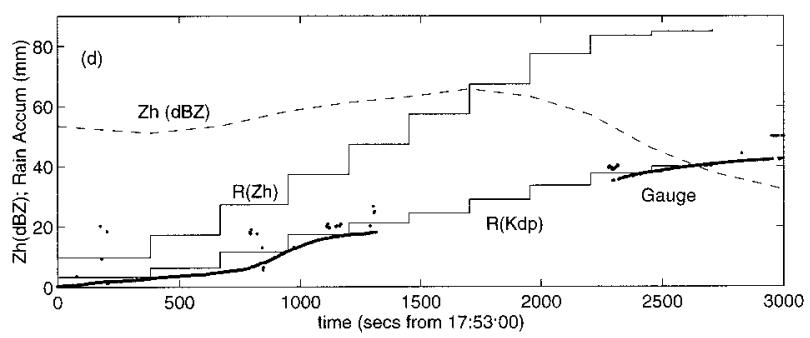

FIG. 11. Time series of (a) $Z_{h}$ and $Z_{\mathrm{DR}}$, (b) $K_{\mathrm{DP}}$ and LDR, and (c) $\rho_{h v}$ over the chase van location marked by " $X$ " in Figs. 3b and $4 \mathrm{~b}$. Data obtained from the $1^{\circ}$ elevation sweep (altitude $\approx 350 \mathrm{~m} \mathrm{AGL}$ ). Except for LDR, the radar values are averaged over a circular area of $1-\mathrm{km}$ diameter centered over the chase van location. The LDR values are taken from a resolution volume in the $1^{\circ}$ elevation angle sweep that is closest to the van location. (c) Visual observations (made by van personnel) of hydrometeor type are marked versus time. The two solid triangles mark the time interval 1803-1808 during which hailstones were collected with the hail catcher net system. (d) $\mathrm{Cu}$ mulative rainfall amounts using the $Z_{h}=300 R^{1.4}$ relation truncated at $55 \mathrm{dBZ}$ and the $R\left(K_{\mathrm{DP}}\right)$ algorithm. The Young capacitance gauge data are also shown (gap in data was caused by power supply problem to the PC). The dashed line shows $Z_{h}$.

field (1987a) to compute polarimetric radar variables as a function of the slope of the hail size distribution at various heights below the $0^{\circ} \mathrm{C}$ level (where hail was initialized in the melting model). Their model scattering calculations predict that at a distance of approximately $2.7 \mathrm{~km}$ below the $0^{\circ} \mathrm{C}$ level (which is about ground level for the present case), the LDR $\approx-14 \mathrm{~dB}, \rho_{h v} \approx 0.92$, and $Z_{\mathrm{DR}} \approx-0.8 \mathrm{~dB}$ for $\Lambda$ $\approx 0.3 \mathrm{~mm}^{-1}$, which is in reasonable agreement with our radar measurements in Fig. 11 at 1500 s. The hail size distribution estimated from the hail collected by the roof-mounted net between 1803 and 1808 MDT (before the largest hail hit the van) is shown in Fig. 12 as the solid line. The fall speeddiameter relation from Matson and Huggins (1980) was used to arrive at the distribution. The dasheddotted line between 20 and $35 \mathrm{~mm}$ has a slope of $0.3 \mathrm{~mm}^{-1}$ and is an estimate of the slope of the large size part of the distribution. This slope is in good agreement with the slope of the distribution between 10 and $22 \mathrm{~mm}$. Using these estimates, the radar measurements and the estimated hail distribution slope are in good agreement with the model scattering results of Aydin and Zhao (1990) applied to this event. The dashed line in Fig. 12 is the Marshall-Palmer (1948) raindrop size distribution corresponding to a rain rate of $80 \mathrm{~mm} \mathrm{~h}^{-1}$ (or $K_{\mathrm{DP}} \approx 2.5^{\circ} \mathrm{km}^{-1}$ ). It is shown here to complete the composite size distri- 
bution of rain and hail in the period 1803-1808 MDT.

3) The polarimetric radar data during periods prior to and after the large hailfall event are in good agreement with scattering models.

From 0 to 1000 s (1753-1809 MDT), the LDR increases gradually from -27 to $-20 \mathrm{~dB}$ in agreement with visual observations of increasing hail size from pea to marble to golfball. The rainfall rate also increases from 30 to $80 \mathrm{~mm} \mathrm{~h}^{-1}$ with $Z_{\mathrm{DR}}$ in the range of $1.3-2.5 \mathrm{~dB}$. The $\rho_{h v}$ decreases from 0.96 to 0.93 in agreement with calculations by Balakrishnan and Zrnić (1990b) for rain mixed with hail. After the large hailfall period, and in agreement with visual observations of reducing hailfall at $2000 \mathrm{~s}$ (1826), the $Z_{\mathrm{DR}}$ shows an increasing trend to positive values, LDR decreases to $-27 \mathrm{~dB}$ and $\rho_{h v}$ increases to $0.97-$ 0.98 , all characteristic of the transition from rain mixed with hail to rain only (Balakrishnan and Zrnić 1990a).

\section{Summary}

Polarimetric radar measurements in a severe hailstorm were analyzed using the recently modified CSUCHILL radar system permitting, for the first time, the combined use of $Z_{h}, Z_{\mathrm{DR}}, \mathrm{LDR}, K_{\mathrm{DP}}$, and $\rho_{h v}$ to infer hydrometeor types and storm structure. A hail chase van, equipped for manual collection of hailstones and instrumented with a rain gauge, intercepted the storm for a period of $50 \mathrm{~min}$. The hailstone size distribution was computed over a period of 5 min before golfballsized hail $\left(D_{\max } \approx 5 \mathrm{~cm}\right)$ damaged the roof-mounted net. However, visual observations of hail sizes during the passage of the entire event over the van were available. The period of golfball-sized hailfall was easily distinguished by high LDR $(\geq-18 \mathrm{~dB})$, negative $Z_{\mathrm{DR}}$ $(\leq-0.5 \mathrm{~dB})$, and lowered $\rho_{h v}(\leq 0.93)$, and these values were consistent with the scattering model results of Aydin and Zhao (1990). This model, when applied to our surface level measurements of golfball hail, gave the slope of an exponential hail-size distribution $(\Lambda=0.3$ $\mathrm{mm}^{-1}$ ), which agreed remarkably well with the slope of the measured hail-size distribution at large sizes $(D$ $\geq 10 \mathrm{~mm}$ ). Rainfall accumulation over the entire event estimated using a $K_{\mathrm{DP}}$-based algorithm was in excellent agreement with the gauge amount $(40 \mathrm{~mm})$, whereas a simple $Z_{h}-R$ relation truncated at $55 \mathrm{~dB} Z$ yielded nearly twice the gauge value. Limited dual-Doppler synthesis at 1747 and 1812 MDT using CSU-CHILL and Denver WSR-88D radars permitted estimates of the horizontal wind and its convergence to be made at the lower altitudes $(\leq 3 \mathrm{~km})$. Location of peak horizontal convergence was used as a proxy for updrafts, and at 1812 MDT a well-defined positive $Z_{\mathrm{DR}}$ column was noted nearly centered on the location of peak convergence (6.5 $\left.\times 10^{-3} \mathrm{~s}^{-1}\right)$. Vertical sections oriented parallel to the low-level inflow and containing the positive $Z_{\mathrm{DR}}$ column were used to infer hydrometeor types in some regions. A persistent positive $K_{\mathrm{DP}}$ column observed on the western fringe of the main updraft was inferred to mark a region of raindrops shed by wet hailstones. The initial development of the positive $Z_{\mathrm{DR}}$ column was documented via volume scans of the storm at about 5-min intervals. Also, a series of high-resolution constant azimuth RHI scans through the WER/inflow region captured the intensification of the positive $Z_{\mathrm{DR}}$ column. These RHIs, together with the constructed $2 \mathrm{D}$ wind vectors at low elevations, suggest that the oblate particles (raindrops or water-covered ice) responsible for the positive $Z_{\mathrm{DR}}$ column descended from the upwind reflectivity overhang (as graupel) and were captured by the cyclonic flow into the storm updraft.

The location of the positive $Z_{\mathrm{DR}}$ column across the low-level inflow places these raindrops in a favorable position to be lofted and become hail embryos in agreement with Conway and Zrnić (1993) and Miller et al. (1990). A general relationship between large hail production and the positive $Z_{\mathrm{DR}}$ column was demonstrated via a plot of the swath of large hail near the surface together with the swath of positive $Z_{\mathrm{DR}}$ at 3.5$\mathrm{km}$ altitude. Additionally, the swath of the LDR cap was plotted at an altitude of $4.5 \mathrm{~km}$, which lined up and was completely contained within the positive $Z_{\mathrm{DR}}$ swath. The interface zone (3- to 5-km altitude for this case) is a mixed-phase region consisting of supercooled and freezing raindrops together with asymmetric wet graupel that are being advected into the storm. Thin section analysis of a sample of the collected hailstones revealed that $30 \%-40 \%$ of the large hailstones $(D \geq 30 \mathrm{~mm})$ had frozen drop embryos. It appears that the positive $Z_{\mathrm{DR}}$ column marks an area of the updraft where frozen drop embryos are produced, and since $30 \%-40 \%$ of the large hailstones in our sample had raindrop embryos, a relationship between between large hail production and the $Z_{\mathrm{DR}}$ column seems evident, at least in this case study. Still $60 \%-70 \%$ of the large hail samples had embryos other than that could be identified as raindrops, for example, graupel, ice, or partially melted ice particle. Since the upper portion of the $Z_{\mathrm{DR}}$ column probably consisted of mixed-phase particles, then it is likely that some of the frozen and partially melted particles became embryos for the above $60 \%-70 \%$ category. Conway and Zrnić (1993) discuss various trajectories through their $Z_{\mathrm{DR}}$ column that could supply various embryo types. Another potential source of raindrop embryos was water shed from wet hail and these shed drops were identified by a positive $K_{\mathrm{DP}}$ column located in the west fringe of the main updraft that was coincident with large reflectivities and high LDR (i.e., a hail signature). The importance of shed drops has been modeled previously (Rassmussen and Heymsfield 1987a,b), but this is the first reported radar evidence of such drops. Thus raindrop embryos may originate 
either in the $Z_{\mathrm{DR}}$ column or the $K_{\mathrm{DP}}$ column, and it is impossible to determine which source is dominant at least in this case study where full three-dimensional wind field analysis was not available. Finally, it is worth noting that for some hailstorms the drops shed from large wet hail could be low enough in concentration that they would not be detectable using $K_{\mathrm{DP}}$ and also would not produce a positive $Z_{\mathrm{DR}}$ signature due to the presences of the dominant hail signature, yet potential raindrop embryos would be present.

Acknowledgments. The CSU-CHILL radar is operated by Colorado State University via a cooperative agreement with the National Science Foundation ATM9500108. Dr. Eugene Mueller and Mr. Dave Brunkow spearheaded the radar modifications with excellent support provided by Mr. Bob Bowie and Mr. Ken Pattison of the CSU-CHILL staff. The hail chase van effort was funded by the Center for Geosciences Phase II at CSU via Grant DAAH04-94-G-0420. Two of the authors (JH and VNB) were supported by this grant and via a grant from the AFOSR (F49620-95-1-0133). LDC would like to acknowledge the support of Prof. Steven Rutledge under NSF Grant ATM-932136. S. Bolen was supported by the Rome Laboratory of the U.S. Air Force. The authors acknowledge the assistance rendered by Dr. Pat Kennedy and Prof. Steven Rutledge of CSU for directing the van for storm intercept. Dr. Charles Knight provided instruction and assistance in the thin section analysis of the hailstones, which was done at the NCAR facilities in Boulder, Colorado. NCAR also provided the GPS units and the hail net. Dr. J. Beaver and Mr. D. Flanigan helped with the scattering model calculations and figures. Mr. Charlie Wilkens installed the hail collection apparatus shown in Fig. 10.

\section{APPENDIX A}

\section{CSU-CHILL Radar}

The CSU-CHILL radar is operated by Colorado State University as a national facility under a cooperative agreement with the National Science Foundation. Under the leadership of E. Mueller and D. Brunkow, the radar underwent a significant modification in 1994-95, including installation of a new dual-polarized antenna as well as a second transmitter (obtained from the National Severe Storms Laboratory) and receiver system. These modifications were completed in the spring of 1995. The radar is now configured as a two transmitter/two receiver system thus eliminating the need for a high-power polarization switch. The two receivers are used for copolar and cross-polar signal reception via an input transfer switch that routes the $\mathrm{HH}$ and $\mathrm{VV}$ signals into the copolar receiver and the $\mathrm{VH}$ and $\mathrm{HV}$ signals into the cross-polar receiver. The radar processor calculates the polarimetric covariance matrix elements up to a
TABLE A1. Characteristics of the CSU-CHILL radar.

\begin{tabular}{ll}
\hline \hline $\begin{array}{l}\text { Antenna } \\
\text { Type }\end{array}$ & $\begin{array}{c}\text { Fully steerable, prime focus para- } \\
\text { bolic reflector }\end{array}$ \\
& $8.5 \mathrm{~m}$ \\
Size & Scalar horn \\
Feed & $1.0^{\circ}$ \\
$3-\mathrm{dB}$ beamwidth & $45 \mathrm{~dB}$ \\
Directivity & $\leq-27 \mathrm{~dB}$ \\
Sidelobe level (any & $\leq-33 \mathrm{~dB}$ \\
$\phi$ plane) &
\end{tabular}

$\phi$ plane)

Polarization radiated

Horizontal or vertical

Transmitter

Type

Wavelength

Peak power

Pulse width

PRT

Max unambiguous range

Max unambiguous velocity

Klystron, modernized FPS-18

$10.7 \mathrm{~cm}$

$700-1000 \mathrm{~kW}$

Steps of $0.1 \mu$ s up to a max. of 1

$\mu \mathrm{s}$

$800-2500 \mu \mathrm{s}$

$375 \mathrm{~km}$

$\pm 34.3 \mathrm{~m} \mathrm{~s}^{-1}$

Receiver

Noise figure $\quad 0.7 \mathrm{~dB}$

Noise power

Typical bandwidth

Transfer function

Dynamic range

$-114 \mathrm{dBm}$

$750 \mathrm{kHz}$

Linear

$90 \mathrm{~dB}, 0-60 \mathrm{~dB}$ IAGC in $12-\mathrm{dB}$ steps
Data acquisition
Signal processor
No. of range gates
Range gate spacing
Sampling rate/avg option
Video digitizer
Time series capability
SP20 made by Lassen Research 64-2048
$0.2 \mu \mathrm{s}$ or $1 \mu \mathrm{s}$
Under microcode control
12-bit, in the SP20 input card for $I, Q$, and $\log P$
Up to 150 range gates
Variables available
Reflectivity at $\mathrm{H}$ polarization $\left(Z_{h}\right)$
Differential reflectivity $\left(Z_{\mathrm{DR}}\right)$
Mean Doppler velocity $(\bar{v})$ and spectral width $\left(\sigma_{v}\right)$
Differential phase between $\mathrm{H}$ and $\mathrm{V}$ states
Copolar correlation coefficient $\left[\rho_{h v}(0)\right]$
Linear depolarization ratio (LDR)
Doppler spectra from FFT processing
$I, Q$, and $\log P$ for every pulse in time series mode (up to 150 gates)

range of $75 \mathrm{~km}$ (the initial range delay can be preset). Table A1 summarizes the system characteristics of the radar. The system linear depolarization ratio limit obtained from measurements is around $-34 \mathrm{~dB}$. Apart from the covariance matrix elements, the radar processor also computes $Z_{\mathrm{DR}}$, LDR, $\Phi_{\mathrm{DP}}$, and $\rho_{h v}$ at resolution volumes spaced $150 \mathrm{~m}$ apart. Typically $64 \mathrm{H}$ and $64 \mathrm{~V}$ polarized samples are used (dwell time of $128 \mathrm{~ms}$ ). The relevant algorithms are given in Doviak and Zrnić (1993).

At each resolution volume the raw data fields of $Z_{h}$, 
$Z_{\mathrm{DR}}, \Phi_{D P}, \mathrm{LDR}$, and $\rho_{h v}$ are available from the weather signal processor. Note that $\rho_{h v}$ here is the magnitude of the copolar correlation coefficient at zero lag (Doviak and Zrnić 1993). Careful examination of the range fluctuations in $\Phi_{D P}$ revealed that it could be used to detect data contamination by several sources but principally by clutter, which can cause large variations in $\Phi_{\mathrm{DP}}$ due to differential backscatter phase (Zrnić and Ryzhkov 1996). To begin processing, raw $\Phi_{\mathrm{DP}}$ range profiles are first examined to identify segments of uncontaminated (or "good") and contaminated (or "bad") data. Using the slope of $\Phi_{\mathrm{DP}}$ and $\rho_{h v}$, the beginning of a good data segment must satisfy slope magnitude less than or equal to $50^{\circ} \mathrm{km}^{-1}$ and $\rho_{h v} \geq 0.90$ over a minimum of five consecutive range gates with $\mathrm{SNR} \geq 10 \mathrm{~dB}$. The end of the good data segment or the beginning of the bad data segment is identified by $\Phi_{\mathrm{DP}}$ slope $>50^{\circ} \mathrm{km}^{-1}$ or $\rho_{h v}<0.9$ or SNR $<10 \mathrm{~dB}$ over three consecutive range gates. Since rain mixed with hail can also give $\rho_{h v}<$ 0.90 , a further check is made based on reflectivity, and mean and standard deviation of $\rho_{h v}$ (mean $\rho_{h v} \geq 0.8, \sigma$ $\leq 0.08$ ) to preserve the hail segment as good data. The $\Phi_{\mathrm{DP}}$ within the bad data segment is approximated by a straight-line fit between the final $\Phi_{\mathrm{DP}}$ value in the good data segment just preceding and the initial $\Phi_{\mathrm{DP}}$ value in the good data segment just following the bad segment. Thus, an initial estimate of $K_{\mathrm{DP}}$ is possible in the bad data segment if precipitation is mixed with clutter. The good data segments for $Z_{\mathrm{DR}}$ and $\rho_{h v}$ are then based on the identified good data segments in $\Phi_{\mathrm{DP}}$. The $\Phi_{\mathrm{DP}}$ data are then iteratively filtered in range following Hubbert and Bringi (1995) to estimate $K_{D P}$. The accuracy in $K_{\mathrm{DP}}$ is estimated at $\pm 0.5^{\circ} \mathrm{km}^{-1}$. The good and bad data segments in LDR range profiles follow the $\Phi_{\mathrm{DP}}$ method with the addition of a minimum copolar SNR of $25 \mathrm{~dB}$ for identifying good data segments. Since LDR is essentially the ratio of the cross-polar returned power to the copolar power, the presence of noise tends to cause a bias in LDR, especially when the SNR in the copolar channel is less than $25 \mathrm{~dB}$.

The radar variables are next interpolated to a Cartesian grid with grid spacing of $0.5 \mathrm{~km}$ along the three orthogonal directions using the NCAR REORDER software package. Vertical sections, such as those depicted in Fig. 6, were obtained using the NCAR CEDRIC display package (Mohr and Miller 1983).

\section{APPENDIX B}

\section{Interpretation of Polarimetric Radar Signatures: An Overview}

A good discussion of multiparameter radar signatures and their interpretation is given in Doviak and Zrnić (1993, chap. 8). Good reviews can be found in Jameson and Johnson (1990) and Herzegh and Jameson (1992). Examples of LDR at $\mathrm{S}$ band together with in situ aircraft verification can be found in Frost et al. (1991). Höller et al. (1994) provide a good discussion of hydrometeor classification using polarimetric radar data at $\mathrm{C}$ band. Bringi et al. (1996) have provided a detailed multiparameter radar study of an intense storm in Colorado using CSU-CHILL and NCAR/CP-2 radar data. Much of their interpretive framework is applied to this paper as well. Multiparameter radar evolution of Florida thunderstorms using CP-2 radar data has been documented recently in Bringi et al. (1997), Jameson et al. (1996), and Ramachandran et al. (1996), especially in relation to the evolution of the positive $Z_{\mathrm{DR}}$ column and LDR cap signatures. Carey and Rutledge (1998) have analyzed the same supercell case (as described in this paper) emphasizing the electrical observations. They have presented their version of a bulk-hydrometeor identification table using $Z_{h}, Z_{\mathrm{DR}}$, LDR, $K_{\mathrm{DP}}$, and $\rho_{h v}$.

Polarimetric radar signatures typically (at low elevation angles $\leq 20^{\circ}$ ) are dependent on the distributions of sizes, shapes, orientations, and dielectric constants of the particles filling the radar resolution volume. Thus, the inverse problem, that is, inference of bulk-hydrometeor types using radar data is complicated with potential ambiguities. Nevertheless, a careful combination of past observations, selected in situ validation using aircraft imaging probes, and scattering model results have greatly improved our ability and confidence in interpretation of radar signatures. Coupled with storm structure and microphysical inferences, which generally place some physical constraints on the inversion, the reliability can be significantly improved. Also, potential ambiguities are generally reduced if the combined set of $Z_{h}, Z_{\mathrm{DR}}, \mathrm{LDR}, K_{\mathrm{DP}}$, and $\rho_{h v}$ are available.

For a distribution of spheroids whose symmetry axes are oriented along the principal polarization axes (horizontal-vertical), that is, the canting angle distribution is narrowly distributed around the horizontal or vertical, the $Z_{\mathrm{DR}}$ is a good measure of the reflectivity-weighted mean axis ratio of the collection of spheroids, though strongly weighted by the dielectric constant (or, equivalently, the particle density). In the case of raindrops, which possess a nearly linear axis ratio versus $D_{\text {eq }}$ relation, the $Z_{\mathrm{DR}}$ is a good estimator of the reflectivityweighted mean drop size.

The LDR for such a collection of nearly oriented spheroids is typically quite low and, for a given axis ratio, is dependent on the variance of the canting angle and the dielectric constant. The relationship among $Z_{\mathrm{DR}}$, LDR, and $\rho_{h v}$ is modeled in appendix E for a collection of partially frozen oblate drops. Jameson et al. (1996) also relate these three variables and give useful graphs. For randomly oriented spheroids in the plane of polarization, a simple relation exists between LDR and $\rho_{h v}$, that is, $\rho_{h v}=1-2 \times 10^{0.1 \mathrm{LDR}}$ (Mead et al. 1991). If the mean canting angle is not aligned along the principal polarization axes (horizontal or vertical), the LDR will increase, attaining maximum, in general, when the particle is tilted $45^{\circ}$. Ambiguities arise in such cases since the shape and orientation effects cannot be decoupled 
using the conventional measurement set. However, hydrometeors that have an axis of symmetry are generally assumed to have mean canting angles near $0^{\circ}$ or $90^{\circ}$. Known exceptions are ice crystals that can be oriented due to strong electric fields. LDR is strongly weighted by the dielectric constant and observations, and modeling studies show that it is possible to distinguish between wet ice particles and "dry" or lower density graupel/snow. The largest values of LDR (and, typically, lowest $\rho_{h v}$ ) are found in the bright band and in large wet hail. They are easily classified based on reflectivity and storm type (stratiform/convective).

For spheroids oriented along the principal polarization axes, the $K_{\mathrm{DP}}$ is proportional to deviations of the axis ratio from unity and the corresponding number concentration of such particles. In rain, $K_{\mathrm{DP}}$ is an excellent estimator of rain rate, even in the presence of hail. Negative $K_{\mathrm{DP}}$ due to vertically oriented ice crystals has been observed (Caylor and Chandrasekar 1996), but typically at mid- to upper levels in thunderstorms and generally not within the higher reflectivity areas. Generally, positive $K_{\mathrm{DP}}$ values are found only well below $0^{\circ} \mathrm{C}$ and typically increase with distance below this level. In this paper, positive $K_{\mathrm{DP}}$ $\left(0.5^{\circ}-1.5^{\circ} \mathrm{km}^{-1}\right)$ found near the $0^{\circ} \mathrm{C}$ level is interpreted as being due to millimeter-sized $(0.5-2 \mathrm{~mm})$ drops shed by large wet hail. Even though the shed drops are nearly spherical, that is, their axis ratio deviation from unity is small, their concentrations are large since large wet hail produces copious numbers of shed drops (Rasmussen and Heymsfield 1987b). This increases the $K_{\mathrm{DP}}$ to measurable levels $\left(0.5^{\circ}-1.5^{\circ}\right.$ $\mathrm{km}^{-1}$ ).

The $\rho_{h v}$ measurement is potentially the most ambiguous when used in isolation since it depends not only on the variance of shapes and orientations but also on Mie scattering effects, that is, variation in scattering differential phase $(\delta)$ across the size distribution. Also, the typical $\rho_{h v}$ estimator based on pulse-pair processing is biased when the Doppler spectra are non-Gaussian (Liu et al. 1994). The range of $\rho_{h v}$, which is typically $0.85-1.0$, is small relative to its measurement accuracy that is around 0.01 . When hydrometeors are predominately of one type, the $\rho_{h v}$ is generally greater than or equal to 0.98 . When mixtures of hydrometeor types are present, for example, bright band or rain mixed with frozen ice particles, the $\rho_{h v}$ decreases from unity.

\section{APPENDIX C}

\section{Effects of Reflectivity Gradients and Antenna Pattern}

It is well known that near regions of large reflectivity gradients, antenna-pattern-induced errors can bias the estimates of $Z_{\mathrm{DR}}, \rho_{h v}$, LDR, and to a smaller extent $\Phi_{\mathrm{DP}}$ (Pointin et al. 1988). Accurate pattern matching within the main lobe is critical for accurate $Z_{\mathrm{DR}}$, and the new antenna has excellent matching of the main lobe (down to $-25-\mathrm{dB}$ level) in all four $\phi$ planes $\left(0^{\circ}, 90^{\circ}\right.$, and $\left.\pm 45^{\circ}\right)$. The sidelobe levels are also a great improvement over the old antenna (Xiao et al. 1988), the worst-case levels being at most $-27 \mathrm{~dB}$ in the $\pm 45^{\circ}$ planes. To estimate the magnitudes of errors in $Z_{\mathrm{DR}}, \mathrm{LDR}$, and $\rho_{h v}$ due to gradients across the antenna beam pattern (i.e., cross-beam reflectivity gradients), we have used as input model cross-beam profiles of $Z_{h}, Z_{\mathrm{DR}}, \rho_{h v}$, and LDR as might typically occur through a hail cell with rain on either side. The antenna patterns measured by the manufacturer (Radiation Systems, Inc.) are convolved with the input radar parameter profiles to estimate the resulting errors. For $Z_{\mathrm{DR}}$, the simplest approximation is

$$
Z_{\mathrm{DR}}=10 \log \left[\frac{\int Z_{h h} f_{h h}^{2} d R}{\int Z_{v v} f_{v v}^{2} d R}\right] \text {, }
$$

where $Z_{h h}$ and $Z_{v v}$ are the input cross-beam reflectivity profiles and $f_{h h}, f_{v v}$ are the (one way) measured power patterns in the azimuthal $\left(\phi=0^{\circ}\right)$ plane. The superscript "sm" on $Z_{\mathrm{DR}}$ (and other variables) refers to simulated values. Note that all reflectivity units used here are in $\mathrm{mm}^{6} \mathrm{~m}^{-3}$. This equation assumes no cross-polar error due to the antenna and is sufficient for evaluation of errors in $Z_{\mathrm{DR}}$ due to mismatches in the main and sidelobes (Herzegh and Carbone 1984). The approximation for LDR is (Blanchard and Newton 1985)

$\mathrm{LDR}^{\mathrm{sm}}$

$$
=10 \log \left[\frac{\int\left[Z_{v h} f_{v v} f_{h h}+Z_{h h} f_{h h} f_{h v}+Z_{v v} f_{v v} f_{v h}\right] d R}{\int Z_{h h} f_{h h}^{2} d R}\right],
$$

where $Z_{v h}$ is the cross-polar reflectivity profile and $f_{h v}$ $=f_{v h}$ is the cross-polar power pattern. Because the $\phi$ $=45^{\circ}$ plane (containing the feed support struts and waveguide runs) is the worst for cross-polar errors, the measured antenna patterns in this plane, as well as in the $\phi=0^{\circ}$ plane, are chosen for estimation of LDR errors. An additional term involving $Z_{v h} f_{v h}^{2}$ is neglected in the numerator of Eq. (C2) since it is small in comparison to the other given terms. To evaluate errors in $\rho_{h v}$, the (one way) antenna differential phase pattern $\left(\phi_{\mathrm{DA}}\right)$ is needed and was measured at the CSU-CHILL site for the new antenna using the procedure described by $\mathrm{Mu}-$ dukutore et al. (1995). An approximation for $\rho_{h v}$ neglecting cross-polar errors is

$$
\rho_{h v}^{\mathrm{sm}}=\frac{\left|\int \sqrt{Z_{v v} Z_{h h}} f_{h h} f_{v v} e^{j 2 \phi_{D A}} d R\right|}{\left\{\int Z_{h h} f_{h h}^{2} d R \int Z_{v v} f_{v v}^{2} d R\right\}^{1 / 2}} .
$$



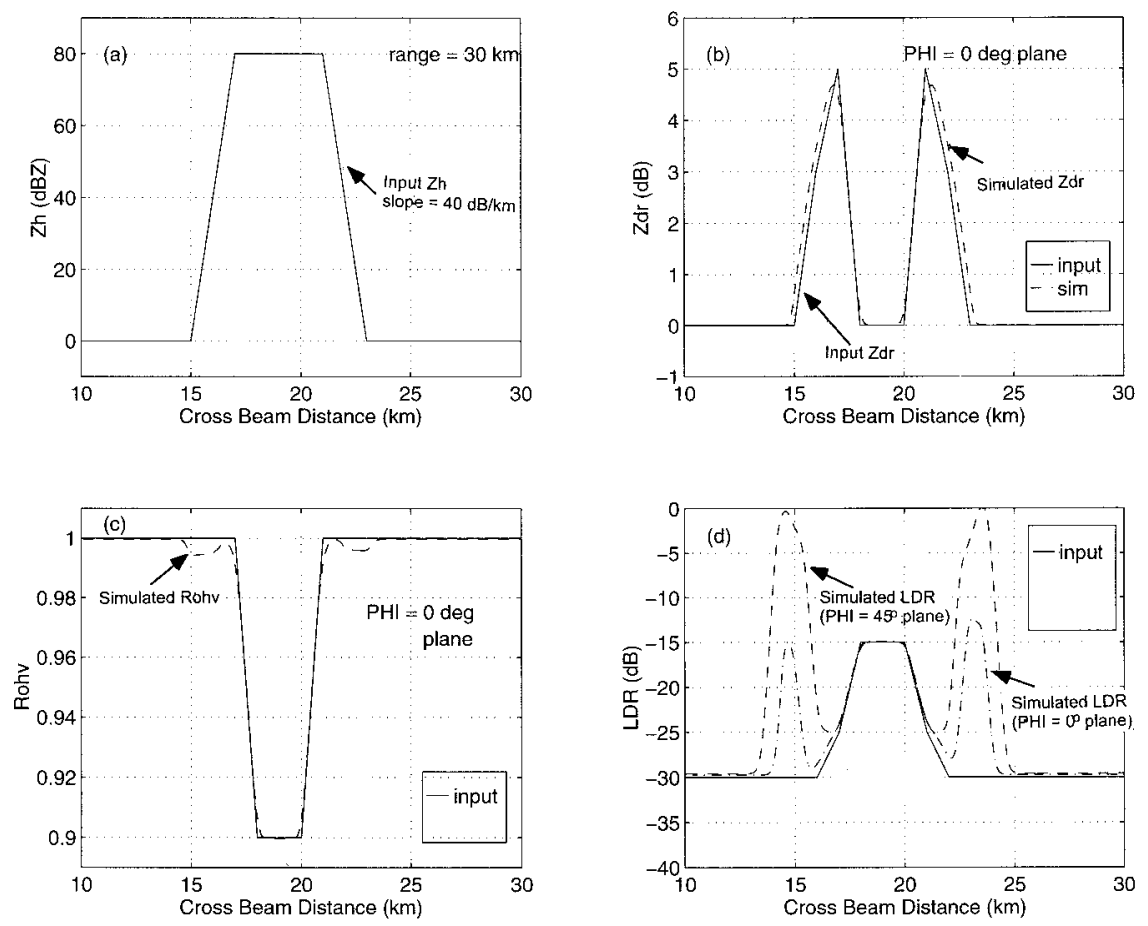

FIG. C1. (a) Input $Z_{h}$ profile with maximum slope of $40 \mathrm{~dB} \mathrm{~km}^{-1}$ along the cross-beam direction. Simulation of antenna-pattern-induced errors are done at a range of $30 \mathrm{~km}$. (b) Input $Z_{\mathrm{DR}}$ profile constructed to represent a hail core $\left(Z_{\mathrm{DR}} \approx 0 \mathrm{~dB}\right)$ surrounded by rain (positive $\left.Z_{\mathrm{DR}}\right)$. Simulated $Z_{\mathrm{DR}}$ uses azimuthal cut $\left(\phi=0^{\circ}\right)$ patterns. (c) Input and simulated $\rho_{h v}$ profiles using $\left(\phi=0^{\circ}\right)$ patterns. (d) Input LDR profile shown as a solid line. Simulations are done using both the $\phi=$ $45^{\circ}$ cut patterns (worst-case plane for cross-polar errors) and $\phi=0^{\circ}$ (azimuth) cut patterns.

The four panels in Fig. C1 show the simulation results. Figure $\mathrm{C} 1$ a shows the input $Z_{h}$ profile versus cross-beam distance at a range of $30 \mathrm{~km}$ from the radar. The gradient in $Z_{h}$ is chosen as $40 \mathrm{~dB} \mathrm{~km}{ }^{-1}$, which is generally in the range of gradient encountered near the the bounded weak echo region or on the inflow side of the storm. The input $Z_{\mathrm{DR}}, \rho_{h v}$, and LDR profiles (shown in Figs. $\mathrm{C} 1 \mathrm{~b}-\mathrm{d}$ are chosen to approximately the conditions typical of a hailshaft surrounded by rainfall. The simulated $Z_{\mathrm{DR}}^{\mathrm{sm}}$ is shown in Fig. C1b, and the errors are seen to be negligible at this range $(30 \mathrm{~km})$ with the simulated profile [via Eq. (C1)] following the input $Z_{\mathrm{DR}}$ very well. Similarly in Fig. C1c the simulated $\rho_{h v}^{\mathrm{sm}}$ follows the input $\rho_{h v}$ profile quite well except for small areas near the $Z_{h}$ gradients (e.g., $15-17 \mathrm{~km}$ ). Even here the errors are around 0.005 , which are well within the measurement standard error [typically 0.01; Liu et al. (1994)]. The most significant errors are in Fig. C1d, which shows $\mathrm{LDR}^{\mathrm{sm}}$ via Eq. (C2) using measured patterns in the $\phi$ $=0^{\circ}$ and $45^{\circ}$ planes. Large errors are noted as expected near the $Z_{h}$ gradients (e.g., near $15 \mathrm{~km}$ ), where input LDR is flat at $-30 \mathrm{~dB}$. In Eq. (C2) the errors are due to the $Z_{h h} f_{h h} f_{h v}$ and $Z_{v v} f_{v v} f_{v h}$ terms. Once the input LDR starts increasing, the errors reduce rapidly. For example, the $\mathrm{LDR}^{\mathrm{sm}}$ profile (using $\phi=0^{\circ}$ plane pattern) matches the input LDR with minimal error $(\leq 2 \mathrm{~dB})$ as soon as input LDR increases from -30 to $-25 \mathrm{~dB}$. Here the errors are due to the term $Z_{v h} f_{v v} f_{h h}$ in Eq. (C2), that is, smoothing of the input LDR profile by the copolar pattern. The actual errors are likely to be bounded by the $\phi=0^{\circ}$ and $\phi=45^{\circ}$ plane results. Also, errors would be minimized if the LDR increased with increase in $Z_{h}$ rather than having a flat, very low value of LDR near the maximum $Z_{h}$ gradients were reduced to $20 \mathrm{~dB} \mathrm{~km}^{-1}$. Thus, in this paper we have used $\left|\nabla Z_{h}\right| \geq 20 \mathrm{~dB} \mathrm{~km}^{-1}$ as a threshold to flag bad LDR areas. The $\nabla Z_{h}$ is computed after interpolating to a Cartesian grid using REORDER and thus are not true cross-beam gradients. In this sense we have been conservative. However, this is offset by not knowing the true $Z_{h}$ gradients, which would be larger in magnitude than the measured $Z_{h}$. On balance, we believe a choice of $\left|\nabla Z_{h}\right| \leq 20 \mathrm{~dB} \mathrm{~km}^{-1}$ is conservative.

\section{APPENDIX D}

\section{Dual-Doppler Analysis}

The National Weather Service WSR-88D radar located close to Denver International Airport also scanned this storm; however, the WSR-88D scans were not dedicated to this cell and therefore a full dual-Doppler anal- 
ysis and resulting three-dimensional reconstruction of the wind field is not possible. Despite this, an estimate of the horizontal velocity vector at low altitudes (0.53.0) $\mathrm{km}$ AGL) was possible at 1747 and 1812 MDT by accomplishing a dual-Doppler analysis using low elevation angle tilts from the CSU-CHILL and Denver WSR-88D radars. Analyses at other times were not possible because the radars were not temporally synchronized and because the supercell moved through the baseline. Note that the baseline between the radars was approximately $75 \mathrm{~km}$. As a result, only gross mesoscale motion (resolvable scale of about $6 \mathrm{~km}$ ) can be inferred due to poor spatial resolution.

After removing ground clutter and unfolding the radial velocities, the radar volumes were interpolated to a common Cartesian grid centered on the supercell with a grid spacing in the horizontal of $1 \mathrm{~km}$ and in the vertical of $0.5 \mathrm{~km}$. A dual-Doppler wind field synthesis was accomplished using the NCAR CEDRIC software (Mohr and Miller 1983). Horizontal wind components $(\mathbf{u}, \mathbf{v})$ were computed from the interpolated radial velocity data at grid points where the crossing angle exceeded $30^{\circ}$. An attempt was made to remove the bias on this estimate of the horizontal wind due to particle terminal fall speeds $\left(V_{t}\right)$ by using a first-guess vertical motion field based on the reflectivity-particle fall speed relation of Marks and Houze (1987). This relationship does not apply well to hailstones. However, since the elevation angles to the features of interest (e.g., convergent storm inflow in the vicinity of the positive $Z_{h h}$ columns) were low $\left(<7^{\circ}\right)$, the effects of particle fall speeds on horizontal velocities are minimal. Therefore, the exact form of the relationship between $Z_{\mathrm{DR}}$ and $V_{t}$ is not critical, as was verified with several sensitivity tests. Since the vertical echo coverage of the supercell was inadequate, no attempt was made to diagnose vertical motions via an integration of the continuity equation.

Low-level horizontal convergence was calculated as a proxy for updraft location and relative strength using the estimated $\mathbf{u}$ and $\mathbf{v}$ winds using CEDRIC. The derived horizontal convergence at a single level $(3 \mathrm{~km}$ AGL in Figs. 3 and 4) may not line up exactly with the center of the updraft core. Depending on the location and strength of the convergence pattern at each level, the position of the updraft can vary relative to the convergence at a given level. In our case, the convergence patterns from the lowest measured level $(0.5 \mathrm{~km})$ to above cloud base $(3 \mathrm{~km})$ were nearly vertically aligned. An approximate estimate of the peak updraft speed and location at the 3-km level was made at 1747 and 1812 MDT. To do this, we assumed a boundary condition of $0 \mathrm{~m} \mathrm{~s}^{-1}$ at the ground and integrated the anelastic continuity equation upward. At 1747 MDT the peak updraft speed was estimated to be $16 \mathrm{~m} \mathrm{~s}^{-1}$ and its location was approximately $3 \mathrm{~km}$ to the northeast of the peak convergence at that level (see Fig. 3b; the bold "+" marks the approximate center of the center of the BWER re- gion at $4.5 \mathrm{~km} \mathrm{AGL).} \mathrm{At} 1812$ MDT the peak updraft speed was estimated at $18 \mathrm{~m} \mathrm{~s}^{-1}$ and was essentially collocated with the peak convergence at the same level (see Fig. 4b; the bold "+" marks the approximate center of the BWER at $5.5 \mathrm{~km} \mathrm{AGL).} \mathrm{In} \mathrm{this} \mathrm{particular} \mathrm{storm,}$ we believe that the horizontal convergence pattern at 3 $\mathrm{km}$ is a useful proxy for the updraft location.

\section{APPENDIX E}

\section{Modeling Partially Frozen Raindrops}

Raindrops can freeze in two patterns depending on the wet bulb temperature: 1 ) above $-4^{\circ}$ to $-5^{\circ} \mathrm{C}$, initial freezing on the bottom and then extending around the liquid core then inward and 2) below $-4^{\circ}$ to $-5^{\circ} \mathrm{C}$, freezing occurs simultaneously around the surface (Blanchard 1957). We model partially frozen raindrops by concentric two-layer oblates such that their axis ratios are equal and the equivolumetric diameters differ by $1 \mathrm{~mm}$. The inside layer is liquid with dielectric constant of water and the outside shell is solid with the dielectric constant of ice. Figure E1 shows $Z_{\mathrm{DR}}$ and $\delta$ (differential backscatter phase) as a function of equivalent diameter. Note that the maximum $Z_{\mathrm{DR}}$ is approximately $6 \mathrm{~dB}$, while $\delta$ is negligible. While in this paper we have not used radar measurements of $\delta$ to detect Mie scattering effects, the processing algorithms do, in fact, yield $\delta$ (Hubbert and Bringi 1995; Zrnić et al. 1993). Next, the exponential size distribution $\left[N(D)=N_{0} e^{-3.67 D / D_{0}}\right.$, where $N_{0}=0.08 \mathrm{~cm}^{-1} \mathrm{~m}^{-3}$ and $\left.D_{0}=2 \mathrm{~cm}\right]$ is assumed, and this size distribution is integrated for Fisher orientation distributions with various standard deviations of canting angle about a mean canting angle of zero, that is, the ensemble mean orientation is vertical [see Mardia (1972) and Hubbert and Bringi (1996) for details of Fisher distribution]. The resulting radar parameters are given in Table E1. Ensembles of partially frozen raindrops can simultaneously have large $Z_{\mathrm{DR}}$ and LDR values with lowered $\rho_{h v}$ such

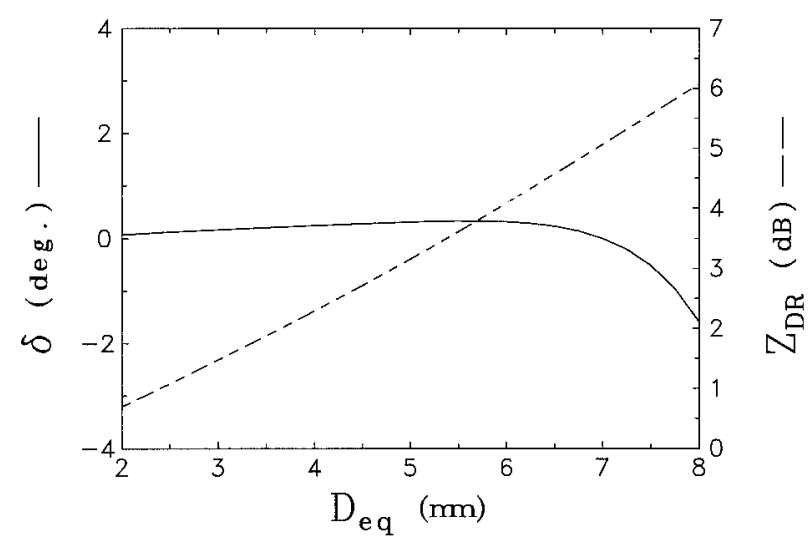

FIG. E1. Shown are $Z_{\mathrm{DR}}$ and $\delta$ (backscatter differential phase) for ice-coated raindrops versus equivolumetric diameter. The $\delta$ is shown for completeness. 
TABLE E1. Various radar parameters for ice-coated water particles integrated over $D=2-8 \mathrm{~mm}$ for an exponential size distribution and a Fisher orientation distribution for various standard deviations of canting angle. Mean canting angle is zero.

\begin{tabular}{ccccc}
\hline \hline $\begin{array}{c}\text { Std } \\
\text { dev } \\
(\mathrm{deg})\end{array}$ & $Z_{\mathrm{DR}}(\mathrm{dB})$ & LDR $(\mathrm{dB})$ & $\rho_{h v}$ & $\delta(\mathrm{deg})$ \\
\hline 10 & 4.68 & -26.17 & 0.9945 & -0.26 \\
15 & 4.41 & -22.97 & 0.9940 & -0.27 \\
20 & 4.06 & -20.92 & 0.9921 & -0.27 \\
25 & 3.64 & -19.56 & 0.9886 & -0.27 \\
30 & 3.18 & -18.67 & 0.9838 & -0.26 \\
35 & 2.71 & -18.11 & 0.9784 & -0.23 \\
40 & 2.26 & -17.79 & 0.9735 & -0.20 \\
45 & 1.85 & -17.62 & 0.9696 & -0.17 \\
50 & 1.49 & -17.56 & 0.9671 & -0.14 \\
55 & 1.19 & -17.55 & 0.9656 & -0.12 \\
60 & 0.94 & -17.58 & 0.9649 & -0.09 \\
\hline
\end{tabular}

as found near the top of positive $Z_{\mathrm{DR}}$ columns. One explanation is that the large raindrops in the $Z_{\mathrm{DR}}$ column are being carried aloft by the strong updraft. As these particles rise they eventually begin to freeze, which can take a minute or more (Smith et al. 1995; Blanchard 1957). The initial ice coating causes the particles to lose their stable orientation (Blanchard 1957) thus increasing the standard deviation of the canting angle distribution and thereby increasing LDR. The high dielectric constant of the remaining liquid water inside the ice coating causes LDR to be much higher than if the particles were solid ice. For example, for frozen drops with the identical orientation and size distribution as used in Table E1 for a standard deviation of canting angle of $40^{\circ}$, the LDR is $-23.5 \mathrm{~dB}$ (instead of $-17.58 \mathrm{~dB}), \rho_{h v}=0.994$, and $Z_{\mathrm{DR}}=1.1 \mathrm{~dB}$. Smith et al. (1995) consider the heat transfer process associated with freezing and conclude that the particles responsible for the high LDR that cap $Z_{\mathrm{DR}}$ columns are partially frozen raindrops rather than graupel in wet growth, as suggested by Herzegh and Jameson (1992).

\section{REFERENCES}

Aydin, K., and Y. Zhao, 1990: A computational study of polarimetric radar observables in hail. IEEE Trans. Geosci. Remote Sens., 28, 412-421.

,-- , and T. A. Seliga, 1990: A differential reflectivity radar hail measurement technique: Observations during the Denver hailstorm of 13 June 1984. J. Atmos. Oceanic Technol., 7, 104113.

— V. V. Bringi, and L. Liu, 1995: Rain-rate estimation in the presence of hail using S-band specific differential phase and other radar parameters. J. Appl. Meteor., 34, 404-410.

Balakrishnan, N., and D. S. Zrnić, 1990a: Estimation of rain and hail rates in mixed-phase precipitation. J. Atmos. Sci., 47, 565-583.

- , and $\longrightarrow, 1990 \mathrm{~b}$ : Use of polarization to characterize precipitation and discriminate large hail. J. Atmos. Sci., 47, 1525-1540.

Blanchard, D. C., 1957: Supercooling, freezing and melting of giant waterdrops in air. Artificial Stimulation of Rain, Proceedings of the First Conference on the Physics of Cloud and Precipitation Particles, Pergamon Press, 223-249.

Blanchard, J., and R. W. Newton, 1985: Demands on polarization purity in the measurement and imaging of distributed clutter. Inverse Methods in Electromagnetic Imaging, W.-M. Boener, Ed., NATO ASI Series C: Mathematical and Physical Sciences, 721-738.

Bluestein, H. B., 1993: Synoptic-Dynamic Meteorology in Mid-latitudes. Vol. II. Observations and Theory of Weather Systems. Oxford University Press, $594 \mathrm{pp}$.

Brandes, E. A., J. Vivekanandan, J. D. Tuttle, and C. J. Kessinger 1995: A study of thunderstorm microphysics with multiparameter radar and aircraft observations. Mon. Wea. Rev., 123, $3129-3143$.

Bringi, V. N., L. Liu, P. C. Kennedy, V. Chandrasekar, and S. A. Rutledge, 1996: Dual multiparameter radar observations of intense convective storms: The 24 June 1992 case study. J. Meteor. Atmos. Phys., 59, 3-31.

—, K. Knupp, A. Detwiler, L. Liu, I. J. Caylor, and R. A. Black, 1997: Evolution of a Florida thunderstorm during the convection and precipitation/electrification experiment: The case study of 9 August 1991. Mon. Wea. Rev., 125, 2131-2160.

Browning, K. A., 1964: Airflow and precipitation trajectories within severe local storms which travel to the right of the winds. $J$. Atmos. Sci., 21, 634-639.

_ 1977: The structure and mechanisms of hailstorms. Hail: A Review of Hail Science and Hail Suppression, Meteor. Monogr., No. 38, Amer. Meteor. Soc., Boston, 1-43.

Carey, L. D., and S. A. Rutledge, 1998: Electrical and multiparameter radar observations of a severe hailstorm. J. Geophys. Res., in press.

Caylor, I. J., and V. Chandrasekar, 1996: Time-varying ice crystal orientation in thunderstorms observed with multiparameter radar. IEEE Trans. Geosci. Remote Sens., 34, 847-858.

Chandrasekar, V., V. N. Bringi, N. Balakrishnan, and D. S. Zrnić, 1990: Error structure of multiparameter radar and surface measurements of rainfall. Part III: Specific differential phase. J. Atmos. Oceanic Technol., 7, 621-629.

Cheng, L., and M. English, 1983: A relationship between hailstone concentration and size. J. Atmos. Sci., 40, 204-213.

Conway, J. W., and D. S. Zrnić, 1993: A study of embryo production and hail growth using dual-Doppler and multiparameter radars. Mon. Wea. Rev., 121, 2511-2528.

Doswell, C. A., 1980: Synoptic-scale environments associated with high plains severe thunderstorms. Bull. Amer. Meteor. Soc., 61, 1388-1399.

Doviak, R. J., and D. S. Zrnić, 1993: Doppler Radar and Weather Observations. 2d ed. Academic Press, 562 pp.

Frost, I. R., J. W. F. Goddard, and A. J. Illingworth, 1991: Hydrometeor identification using crosspolar radar measurements and aircraft verification. Preprints, 25th Conf. on Radar Meteorology, Paris, France, Amer. Meteor. Soc., 658-661.

Galloway, A., A. Pazmany, J. Mead, R. E. MacIntosh, D. Leon, R. Kelly, and G. Vali, 1997: Dectection of ice hydrometeor alignment using an airborne w-band polarimetric radar. J. Atmos. Oceanic Technol., 14, 3-12.

Herzegh, P. H., and R. E. Carbone, 1984: The influence of antenna illumination function characteristic on differential reflectivity measurements. Preprints, 22d Conf. on Radar Meteorology, Zürich, Switzerland, Amer. Meteor. Soc., 281-286.

, and A. R. Jameson, 1992: Observing precipitation through dualpolarization measurements. Bull. Amer. Meteor. Soc., 73, 13651374.

Höller, H., V. N. Bringi, J. Hubbert, M. Hagen, and P. F. Meischner, 1994: Life cycle and precipitation formation in a hybrid-type hailstorm revealed by polarimetric and Doppler radar measurements. J. Atmos. Sci., 51, 2500-2522.

Hubbert, J., and V. N. Bringi, 1995: An iterative filtering technique for the analysis of copolar differential phase and dual-frequency radar measurements. J. Atmos. Oceanic Technol., 12, 643-648. - and - 1996: Specular null polarization theory: Applications to radar meteorology. IEEE Trans. Geosci. Remote Sens., 34, 859-873. 
Husson, D., and Y. Pointin, 1989: Quantitive estimation of the hail fall intensity with a dual polarization radar and a hail pad network. Preprints, 24th Conf. on Radar Meteorology, Tallahassee, FL, Amer. Meteor. Soc., 318-321.

Jameson, A. R., 1983: Microphysical interpretation of multi-parameter radar measurements in rain. Part I: Interpretation of polarization measurements and estimation of raindrop shapes. J. Atmos. Sci., 40, 1792-1802.

— in Meteorology, D. Atlas, Ed., Amer. Meteor. Soc., 323-347.

—, M. J. Murphy, and E. P. Krider, 1996: Multiple-parameter radar observations of isolated Florida thunderstorms during the onset of electrification. J. Appl. Meteor., 35, 343-354.

Joe, P. I., and R. List, 1984: Numerical modelling of rain to hail conversion. Proc. Ninth Int. Cloud Phys. Conf., Tallinn, USSR, International Association of Meteorology and Atmospheric Physics, 261-265.

Kelsh, M., 1989: An evaluation of the NEXRAD hydrology sequence for different types of convective storms in northeastren Colorado. Preprints, 24th Conf. on Radar Meteorology, Tallahassee, FL, Amer. Meteor. Soc., 207-210.

Knight, C. A., and N. C. Knight, 1970: Hail stone embryos. J. Atmos. Sci., 27, 659-666.

- W. Cooper, D. Breed, I. Paluch, P. Smith, and G. Vali, 1982: Microphysics. Hail Storms of the Central High Plains: The National Hail Experiment, C. Knight and P. Squires, Eds., Vol. I, Colorado Assoc. University Press., 151-193.

Knight, N. C., 1981: The climatology of hailstones embryos. J. Appl. Meteor., 20, 750-755.

Lesins, G. B., R. List, and P. I. Joe, 1980: Ice accretions. Part I: Testing of new atmospheric icing concepts. J. Rech. Atmos., 14, 347-356.

Liu, L., V. N. Bringi, V. Chandrasekar, E. A. Mueller, and A. Mudukotore, 1994: Analysis of the copolar correlation coefficient between horizontal and vertical polarizations. J. Atmos. Oceanic Technol., 11, 950-963.

Macklin, W. C., 1977: The characteristics of natural hailstones and their interpretation. Hail: A Review of Hail Science and Hail Suppression, Meteor. Monogr., No. 38, Amer. Meteor. Soc., 6588.

Mardia, K. V., 1972: Statistics of Directional Data. Academic Press, $357 \mathrm{pp}$.

Marks, F. D., Jr., and R. A. Houze, 1987: Inner core structure of Hurricane Alicia from airborne Doppler radar observations. $J$. Atmos Sci., 44, 1296-1317.

Marshall, J. S., and W. Palmer, 1948: The distribution of raindrops with size. J. Meteor., 5, 165-166.

Matson, R. J., and A. W. Huggins, 1980: The direct measurement of the sizes, shapes and kinematics of falling hailstones. J. Atmos. Sci., 37, 1107-1124.

Mead, J. B., P. M. Langglois, P. S. Chang, and R. E. MacIntosh, 1991: Polarometric scattering from natural surfaces at $225 \mathrm{GHz}$. IEEE Trans. Geosci. and Remote Sens., 39, 1405-1411.

Miller, L. J., J. D. Tuttle, and C. Knight, 1988: Airflow and hail growth in a severe northern high plains supercell. J. Atmos. Sci., 45, 736-762.
,-- , and G. B. Foote, 1990: Precipitation production in a large Montana hailstorm: Airflow and particle growth trajectories. $J$. Atmos. Sci., 47, 1619-1646.

Mohr, C. G., and L. J. Miller, 1983: CEDRIC-A software package for Cartesian space editing, synthesis, and display of radar fields under interactive control. Preprints, 21st Radar Meteorology Conf., Edmonton, AB, Canada, Amer. Meteor. Soc., 569-574.

Moller, A. R., C. A. Doswell III, M. P. Foster, and G. R. Woodall, 1994: The operational recognition of supercell thunderstorm environments and storm structures. Wea. Forecasting, 9, 327-347.

Mudukutore, V., V. Chandrasekar, and E. A. Mueller, 1995: The differential phase pattern of the CSU-CHILL radar antenna. J. Atmos. Oceanic Technol., 12, 1120-1123.

Pointin, Y. C., C. Ramond, and J. Fournet-Fayard, 1988: Radar differential reflectivity $Z_{\mathrm{DR}}$ : A real-case evaluation of errors induced by antenna characteristics. J. Atmos. Oceanic Technol., 5, 416423.

Ramachandran, R., A. Detwiler, P. L. Smith, and V. N. Bringi, 1996: Precipitation development and electrification in Florida thunderstorm cells during CaPE. J. Geophys. Res., 101, 1599-1619.

Rasmussen, R. M., and A. J. Heymsfield, 1987a: Melting and shedding of graupel and hail. Part I: Model physics. J. Atmos. Sci., 44, 2754-2763.

, and $-1987 \mathrm{~b}$ : Melting and shedding of graupel and hail. Part III: Investigation of the role of shed drops as hail embryos in the 1 August CCOPE severe storm. J. Atmos. Sci., 44, 27832803.

Smith, P. L., A. G. Detwiler, D. J. Musil, and R. Ramachandran, 1995: Observations of mixed-phase precipitation within a CaPE thunderstorm. Preprints, Conf. on Cloud Physics, Dallas, TX, Amer. Meteor. Soc., 8-13.

Torlaschi, E., R. G. Humphries, and B. L. Barge, 1984: Circular polarization for precipitation measurement. Radio Sci., 19, 193200

Tuttle, J. D., V. N. Bringi, H. D. Orville, and F. J. Kopp, 1989: Multiparameter radar study of a microburst: Comparison with model results. J. Atmos. Sci., 46, 601-620.

Weisman, M. L., and J. B. Klemp, 1982: The dependence of numerically simulated convective storms in directionally varying wind shears. Mon. Wea. Rev., 110, 504-520.

$\longrightarrow$, and -1984 : The structure and classification of numerically simulated convective storms in directionally varying wind shears. Mon. Wea. Rev., 112, 2479-2498.

Xiao, R., V. N. Bringi, E. A. Mueller, and S. A. Rutledge, 1993: Copolar and crosspolar pattern measurements of the CSUCHILL antenna. Preprints, 26th Int. Conf. on Radar Meteorology, Norman, OK, Amer. Meteor. Soc., 363-365.

Young, K. C., 1993: Microphysical Processes in Clouds. Oxford University Press, $427 \mathrm{pp}$.

Zrnić, D. S., 1987: Three-body scattering produces precipitation signature of special diagnostic value. Radio Sci., 22, 76-86.

_ , and A. V. Ryzhkov, 1996: Advantages of rain measurements using specific differential phase. J. Atmos. Oceanic Technol., 13, 454-464.

, V. N. Bringi, N. Balakrishnan, K. Aydin, V. Chandrasekar, and J. Hubbert, 1993: Polarimetric measurements in severe hailstorm. Mon. Wea. Rev., 121, 2223-2238. 